\title{
Climate Variability of the Intensity of Synoptic Processes in the North Atlantic Midlatitudes
}

\author{
Sergey K. GuleV \\ Institut für Meereskunde, Kiel, Germany, and P. Shirshov Institute of Oceanology, Moscow, Russia
}

(Manuscript received 30 May 1995, in final form 16 July 1996)

\begin{abstract}
Long-term interannual variations of the intramonthly standard deviations of surface meteorological parameters are studied on the basis of the North Atlantic Ocean Weather Stations (OWSs) dataset. To consider the different scales of short-term synoptic variability, intramonthly statistics were calculated for 3-h sampled data and for running-mean data as well. Year-to-year variability is considered in terms of linear trends and interannual oscillations with characteristic periods of several years. Intramonthly standard deviations for most of the parameters tended to decrease during the OWS observational period. Trends in the parameters for different synopticscale statistics are discussed. Intramonthly statistics, computed for different averaging scales, demonstrate remarkably different short-period year to year oscillations. Some relationships between the interannual variations of synoptic activity and the SST anomalies are presented. Intramonthly statistics are found to be an effective indicator of the North Atlantic Oscillation. Finally, the possibility of applying results to statistics computed from climatological datasets and analyses of meteorological centers is discussed.
\end{abstract}

\section{Introduction}

Climatological studies primarily pay attention to long-period changes in air-sea interaction characteristics based on monthly and annual means. However, long-term variations of the statistics of short-period processes can also tell us much about climate changes since these account for the synoptic and mesoscale variability that is especially important in the midlatitudes. Considering long-lived sea surface temperature (SST) anomalies, there is the evidence of both extratropical SST response to the atmospheric forcing and the anomalous SST impact on the atmospheric circulation, although space-time scales of these two mechanisms could be quite different. A number of articles (Hasselmann 1976; Frankignoul and Hasselmann 1977; Frankignoul 1979, 1985; Frankignoul and Reynolds 1983; Elsberry and Camp 1978; Demchenko 1987; Pitterburg 1989) demonstrate that the long-term variations in SST in the midlatitudes can be generated by short-period atmospheric fluctuations. Deser and Blackmon (1993) and Kushnir (1994) have studied the relationships between SST variations and changes in atmospheric circulation in the North Atlantic on interdecadal timescales. Cayan (1992 a-c) and Iwasaka and Wallace (1995) considered anomalies of the ocean-atmosphere fluxes that integrate properties of the sea-air interface and found that the heat

Corresponding author address: S. Gulev, P. Shirshov Institute of Oceanology, RAS, 23 Krasikova str., 117218 Moscow, Russia. E-mail: rocc@sovam.com flux anomalies are linked to both month to month tendencies of the SST anomalies and to the anomalies in atmospheric circulation in the extratropical North Atlantic and North Pacific. All of these works are mostly based on monthly averaged SST and atmospheric data taken usually from the Comprehensive Ocean-Atmosphere Data Set (COADS) or similar archives of gridded marine meteorology. However, even equal monthly means can be associated with higher-frequency variability of different intensities. Recently Zorita et al. (1992) and von Storch et al. (1993) have introduced intramonthly standard deviations of sea level pressure (SLP) in COADS $2^{\circ} \times 2^{\circ}$ boxes as an important indicator of circulation patterns over the North Atlantic, related to the statistics of storms. They found significant lagged correlations of these statistics with the SST anomalies in wintertime. At the same time COADS intramonthly statistics contain contributions from natural synoptic variability and different random errors, which result from observational inaccuracy and incomplete sampling.

Many analyses of cyclone frequencies over the North Atlantic (Reitan 1974; Zishka and Smith 1980; Schinke 1992; and others) indicate long-term changes in the number of cyclones and remarkable year to year variations of the cyclonic activity. These climatic tendencies are important in the context of the considerable debate on the reliability of the growing storminess of the North Atlantic (Schmidt and von Storch 1993; von Storch et al. 1993). According to the concept of the North Atlantic oscillation (NAO), interannual variations in midlatitude 
storms are associated with the NAO extremes, named "Greenland below" (GB) and "Greenland above" (GA) (van Loon and Rogers 1978; Lamb and Peppler 1987; Carleton 1988). Due to data limitation over the ocean, most articles consider indirect information (cyclone frequencies, etc.) to describe the synoptic scale, but the accuracy of storm statistics taken from weather maps is still questionable, especially for severe storms (Agee 1991; Ueno 1993; von Storch et al. 1993).

This study considers the role of short-period synoptic processes in the climatic variability of the midlatitude North Atlantic, on the basis of meteorological data, at the North Atlantic Ocean Weather Stations (OWSs). These data are almost free of the problems associated with changing data coverage and analysis techniques that are typical for analyses based on weather maps (von Storch et al. 1993). OWSs also provide us with a wider choice of variables and make it possible to calculate intramonthly statistics for different ranges of synoptic and mesoscale variability. Long-term changes of these statistics should reflect variations of the intensity of short-period processes, such as the frequency of cyclones from month to month and from year to year. The North Atlantic midlatitudes are characterized by a very intensive synoptic activity of the atmosphere determined by the location of the main North Atlantic storm track. Locations of the North Atlantic OWSs make it possible to study practically all types of North Atlantic cyclones. The NAO is associated with the region $30^{\circ}-70^{\circ} \mathrm{N}, 10^{\circ}-$ $30^{\circ} \mathrm{W}$, where all east Atlantic OWSs are located. The North Atlantic midlatitudes are characterized by strong and relatively long-lived SST anomalies. Thus, we expect that the chosen dataset will be effective in many ways.

\section{Data}

To study the problems described above it is necessary to use homogeneous meteorological data taken continuously at the same locations by known ships with known anemometer levels for the period of at least several years. This dataset should also be of relatively high quality to ensure that the statistics of parameters reflect natural variability and are not connected with inadequate sampling (Legler 1991), irregularity in space and time (Weare 1989; Weare and Strub 1981), or changes in analysis technique, as for weather maps. There are a number of demonstrated difficulties in using voluntary observing ship data (mostly COADS), even for the detection of long-term variations of monthly mean values (Ramage 1984; Jones 1988; Peterson and Hasse 1987; Cardone et al. 1990; Ward 1992; Weare 1993; Isemer 1995; Gulev 1995). Data from OWSs, in contrast to data from voluntary observing ships, provide an exceptional chance to study the variability of intramonthly statistics of meteorological parameters. These data have been used previously for investigations of the annual and interannual variability of mean values of variables
TABLE 1. Information about the number of observations, locations, and observational periods of the North Atlantic OWS datasets used in this study.

\begin{tabular}{|c|c|c|c|c|}
\hline OWS & $\begin{array}{l}\text { Number } \\
\text { of obser- } \\
\text { vations }\end{array}$ & Latitude & Longitude & $\begin{array}{c}\text { Period of } \\
\text { observations } \\
\text { Month/Year }\end{array}$ \\
\hline A & 61920 & $62^{\circ} \mathrm{N}$ & $33^{\circ} \mathrm{W}$ & Jan 1948-Dec 1972 \\
\hline B & 52918 & $56.5^{\circ} \mathrm{N}$ & $51^{\circ} \mathrm{W}$ & Jan 1949-Dec 1972 \\
\hline $\mathrm{C}$ & 113287 & $52.5^{\circ} \mathrm{N}$ & $35.5^{\circ} \mathrm{W}$ & Jan 1946-Dec 1989 \\
\hline $\mathrm{D}$ & 63620 & $44^{\circ} \mathrm{N}$ & $41^{\circ} \mathrm{W}$ & Jan 1950-Dec 1972 \\
\hline $\mathrm{E}$ & 63832 & $35^{\circ} \mathrm{N}$ & $48^{\circ} \mathrm{W}$ & Jan 1950-Dec 1972 \\
\hline $\mathrm{I}$ & 51499 & $59^{\circ} \mathrm{N}$ & $19^{\circ} \mathrm{W}$ & Jan 1955-Dec 1973 \\
\hline $\mathrm{J}$ & 66379 & $52.5^{\circ} \mathrm{N}$ & $20^{\circ} \mathrm{W}$ & Jan 1949-Dec 1973 \\
\hline K & 62814 & $45^{\circ} \mathrm{N}$ & $16^{\circ} \mathrm{W}$ & Jan 1950-Dec 1974 \\
\hline $\mathrm{L}$ & 30115 & $57^{\circ} \mathrm{N}$ & $20^{\circ} \mathrm{W}$ & Jan 1976-Dec 1989 \\
\hline M & 89323 & $66^{\circ} \mathrm{N}$ & $2^{\circ} \mathrm{W}$ & Jan 1950-Dec 1987 \\
\hline $\mathrm{R}$ & 21248 & $47^{\circ} \mathrm{N}$ & $17^{\circ} \mathrm{W}$ & Jan 1977-Dec 1985 \\
\hline
\end{tabular}

and fluxes (Willebrand 1978; Smith and Dobson 1984; Diaz et al. 1987; Isemer 1995).

The data for this study were collected at 11 OWSs in the North Atlantic (A, B, C, D, E, I, J, K, L, M, and R) during the period 1946-89. H.-J. Isemer kindly supplied the author with original 3-h sampled observations of SST, air temperature, wet-bulb temperature, SLP, wind speed and direction, and cloudiness (Isemer 1994). The OWS locations are shown in Table 1. For every OWS a simple process has been applied to exclude reports with missing data and to check for errors in the National Climate Data Center (NCDC) files. Actual periods for which meteorological data were used and the total number of reports without missing data or visible errors are also listed in Table 1. The data for the most of the OWSs and for most months are nearly complete and generally contain more than 200 observations month ${ }^{-1}$. Interested readers can find complete information about the number of missing data points and details of historical changes in observation techniques in Isemer (1994) and Isemer and Lindau (1995). For some estimates the original compressed marine reports (CMRs) available from COADS archives (Slutz et al. 1985) have been used. They contain previously extracted reports in the immediate vicinity of several OWSs and the original NCDC files for a number of $10^{\circ} \times 10^{\circ}$ boxes as well.

\section{Methods to estimate short-period statistics of individual variables and fluxes}

We will consider standard deviations as representative characteristics of intramonthly synoptic variability. Hereafter, we will use the term SSTDs (synoptic standard deviation) to recognize intramonthly statistics. SSTDs of meteorological parameters and fluxes were calculated for every individual month on the basis of 3-h sampled observations for every OWS. To study different synoptic and mesometeorological scales, these calculations were repeated, not only for sampled series, 
but also for series of observations previously averaged with different averaging periods. Figure 1 shows synoptic spectra of air temperature, wind speed, and sea level pressure at OWSs A, D, and J. These spectra and earlier results of Gulev and Kolinko (1990) indicate multiscale synoptic variability. Based on the spectral peaks seen in such plots, it is difficult to select from the beginning appropriate scales for sharing different ranges of synoptic variability. If significant spectral maxima appear, they are close to the periods of 70-90 and $20-40 \mathrm{~h}$, which correspond to the synoptic-scale cyclonic activity and highly transient variability, respectively. For a number of variables (such as air temperature and humidity) a diurnal spectral maximum appears, although it is significantly pronounced primarily during the summertime. We have removed diurnal oscillations from the 3 -h series by performing the multiharmonic model for each individual monthly series (Levin 1974) and the following subtraction of this model from the sampled series. We considered averaging periods of $12,24,48,72,120,180$, and $240 \mathrm{~h}$, each of which has the effect of filtering out the synoptic variability on timescales shorter than the averaging scale. Temporal averaging with a timescale $\tau$ was achieved by taking the running mean of the sampled series $x(t)$ :

$$
\langle x\rangle_{\tau}\left(t_{i}\right)=\frac{1}{\tau} \int_{t_{i}-\tau / 2}^{t_{i}+\tau / 2} x(t) d t .
$$

An important issue is the sensitivity of the results to the choice of low-pass filter. Some comparisons of the use of different filters are given in the appendix. For monthly time series both sampled and filtered with different $\tau$, SSTDs were computed in respect to a monthly mean. An alternative SSTD estimator (Thiebaux 1974) is discussed in the appendix.

To calculate the individual values of sensible heat flux $Q_{H}$, latent heat flux $Q_{E}$, and momentum flux $Q_{V}$, the bulk aerodynamic formulas were used in the following form:

$$
\begin{aligned}
& Q_{H}=C_{p} \rho_{a} C_{T} V \delta T, \quad Q_{E}=L \rho_{a} \frac{0.622}{P} C_{E} V \delta e, \\
& Q_{V}=\rho_{a} C_{V} V^{2},
\end{aligned}
$$

where $\delta T=\mathrm{SST}-T_{a} ; \delta e=e_{o}-e_{z} ; T_{a}$ is air temperature; $e_{z}$ is water vapor pressure; $e_{o}$ is saturation vapor pressure connected with SST; $V$ is wind speed; $\rho_{a}$ is air density; $C_{p}$ is the specific heat of air at constant pressure; $L$ is the latent heat of evaporation of water; and $C_{T}, C_{E}$, and $C_{V}$ are the transfer coefficients determined by integration of equations for velocity, temperature, and humidity distribution near the water surface, using a model for the marine atmospheric surface layer based on Monin-Obukhov similarity theory (Ariel et al. 1981). Comparisons of this method with the often used results of Liu et al. (1979) are presented in Gulev (1994, 1995). Yet one can still ask if the present results depend on the choice of bulk parameterization scheme. Blanc (1985) compared several different schemes on the basis
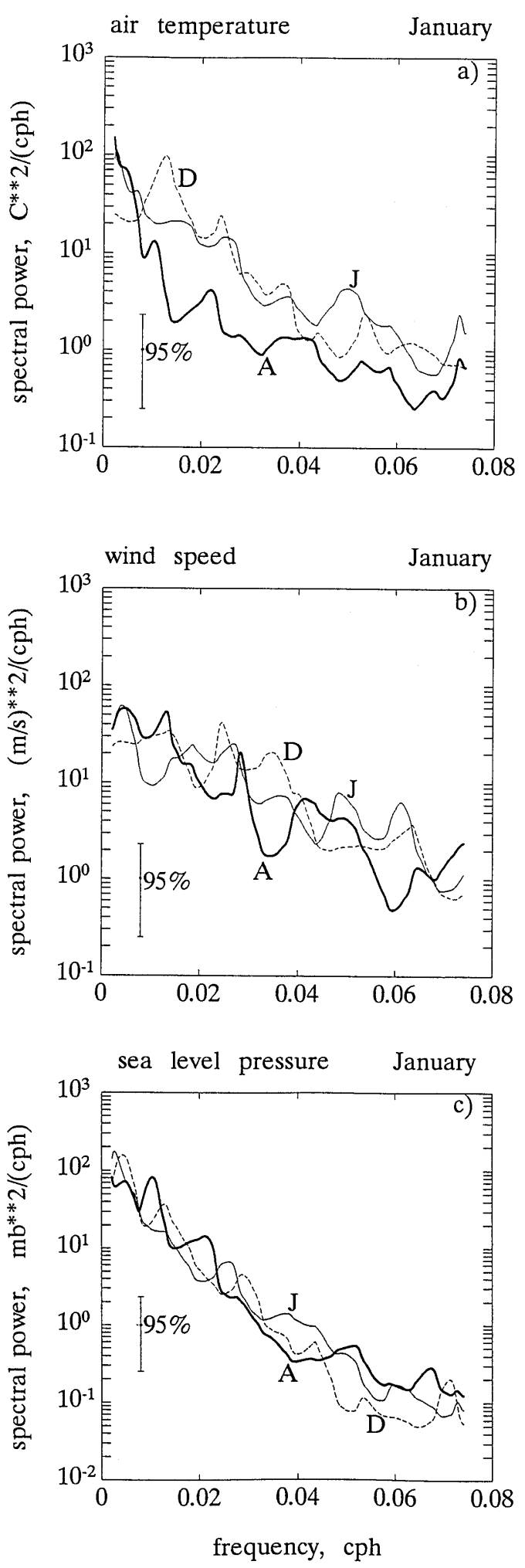

FIG. 1. Spectra of 3-h sampled series of (a) air temperature, (b) wind speed, and (c) sea level pressure at OWSs A (heavy line), J (thin line), and $\mathrm{D}$ (dashed line). 
of 1-yr observations at OWS $\mathrm{C}$ and found a large range of variations from scheme to scheme. Other studies (Husby 1980; Smith and Dobson 1984; Gulev 1995; Kent and Taylor 1995; and others) address the application of different schemes and averaging procedures for different datasets. Scheme to scheme variations appear to be very important for the calculation of climatological means. However, to examine interannual variations of intramonthly statistics of fluxes, it seems more important to choose a single scheme and use it for all of the stations and all observation periods.

For each averaging period, heat, moisture, and momentum fluxes were calculated on the basis of previously smoothed series, and after that intramonthly SSTDs of fluxes were determined for every $\tau$. The alternative possibility was to filter the sampled estimates of fluxes and then calculate SSTD. Differences between these two approaches should be discussed in terms of relationships between so-called sampling and classical methods of flux calculation (Fissel et al. 1977; Esbensen and Reynolds 1981; Marsden and Pond 1983; Hanawa and Toba 1987; Ledvina et al. 1993; Gulev 1994; and others). Our results, computed from previously averaged data, belong to the classical estimates and depart from the sampling fluxes. We will address this problem in the appendix, giving comparisons between the long-term variations of intramonthly synoptic statistics of fluxes taken from sampled and previously averaged data. Thus, for every individual month and every OWS we obtained SSTD values $\left(\sigma_{x}^{\tau}\right)$, where $\tau$ is the averaging period and $x$ corresponds to different parameters such as SST, air temperature, water vapor pressure, SLP, air-sea temperature difference, humidity gradient, wind speed, sensible heat flux, latent heat flux, and momentum flux.

\section{Results}

\section{a. Long-period trends and interannual variability}

Long-term variability of SSTD and its changes with increasing $\tau$ (i.e., from one synoptic scale to another) can be considered in view of linear trend changes and the appearance or disappearance of oscillations with periods of several years for different $\tau$. We consider first long-period trends of SSTD for different parameters and OWSs in order to study 1) whether these long-term changes of statistical properties exist or not, because even if there are significant trends of mean values, trends in high-order statistics may not necessarily be significant, and 2) whether there are any differences between long-term variations of SSTD computed with different previous averaging of sampled data. To consider interannual variability of SSTD and mean values of different parameters, long-term anomalies were obtained using the breakdown technique for monthly time series of Lappo et al. (1987). Every time series is assumed to have the following structure:

$$
x(t)=S(t)+F(t)+\epsilon(t),
$$

TABLE 2. Trends $\left(10^{-2}\langle\mathrm{UNIT}\rangle \mathrm{yr}^{-1}\right)$ of SSTDs of different parameters at the North Atlantic OWSs. Numbers in columns correspond to averaging periods of 3,72 , and $240 \mathrm{~h}$ (from the top to the bottom).

\begin{tabular}{|c|c|c|c|c|}
\hline OWS & $\mathrm{T}_{\mathrm{a}},{ }^{\circ} \mathrm{C}$ & SLP, mb & $\mathrm{V}, \mathrm{m} \mathrm{s}^{-1}$ & $\mathrm{Q}_{\mathrm{E}}, \mathrm{W} \mathrm{m}^{-2}$ \\
\hline A & $\begin{array}{l}0.70^{\mathrm{b}} \\
1.39^{\mathrm{a}} \\
1.15^{\mathrm{b}}\end{array}$ & $\begin{array}{r}-2.09^{\mathrm{b}} \\
2.33^{\mathrm{b}} \\
6.24^{\mathrm{a}}\end{array}$ & $\begin{array}{c}-2.18^{\mathrm{a}} \\
0.25 \\
0.89^{\mathrm{b}}\end{array}$ & $\begin{array}{r}-27.6^{\mathrm{b}} \\
17.7^{\mathrm{c}} \\
19.1^{\mathrm{b}}\end{array}$ \\
\hline B & $\begin{array}{c}0.00 \\
0.02 \\
-0.13^{\mathrm{c}}\end{array}$ & $\begin{array}{l}-2.27^{\mathrm{b}} \\
-2.51^{\mathrm{b}} \\
-0.57\end{array}$ & $\begin{array}{l}-1.18^{\mathrm{a}} \\
-1.09^{\mathrm{b}} \\
-0.55\end{array}$ & $\begin{array}{l}-71.2^{\mathrm{a}} \\
-42.6^{\mathrm{a}} \\
-20.5^{\mathrm{b}}\end{array}$ \\
\hline $\mathrm{C}$ & $\begin{array}{r}-1.53^{\mathrm{b}} \\
-0.17^{\mathrm{c}} \\
0.81^{\mathrm{b}}\end{array}$ & $\begin{array}{r}-3.07^{\mathrm{a}} \\
-2.11^{\mathrm{b}} \\
1.27^{\mathrm{c}}\end{array}$ & $\begin{array}{c}-0.84^{\mathrm{b}} \\
-0.49^{\mathrm{c}} \\
0.32\end{array}$ & $\begin{array}{r}-77.1^{\mathrm{b}} \\
-42.4^{\mathrm{b}} \\
18.3^{\mathrm{c}}\end{array}$ \\
\hline $\mathrm{D}$ & $\begin{array}{l}-1.38^{\mathrm{a}} \\
-0.92^{\mathrm{b}} \\
-0.48^{\mathrm{c}}\end{array}$ & $\begin{array}{l}1.86^{\mathrm{c}} \\
1.90^{\mathrm{b}} \\
1.58^{\mathrm{b}}\end{array}$ & $\begin{array}{l}-0.83^{\mathrm{c}} \\
-0.60^{\mathrm{b}} \\
-0.36\end{array}$ & $\begin{array}{c}-161.2^{\mathrm{b}} \\
-89.7^{\mathrm{b}} \\
-44.1^{\mathrm{c}}\end{array}$ \\
\hline $\mathrm{E}$ & $\begin{array}{l}0.24 \\
0.44^{\mathrm{b}} \\
0.42^{\mathrm{a}}\end{array}$ & $\begin{array}{r}0.86^{\mathrm{b}} \\
0.65^{\mathrm{c}} \\
-0.26^{\mathrm{b}}\end{array}$ & $\begin{array}{r}0.28^{\mathrm{c}} \\
0.36^{\mathrm{b}} \\
-0.50^{\mathrm{b}}\end{array}$ & $\begin{array}{r}17.3^{\mathrm{b}} \\
-3.6^{\mathrm{c}} \\
-14.3^{\mathrm{b}}\end{array}$ \\
\hline $\mathrm{J}$ & $\begin{array}{c}-0.17^{\mathrm{c}} \\
-0.16^{\mathrm{c}} \\
0.10\end{array}$ & $\begin{array}{r}-2.19^{\mathrm{c}} \\
-0.46 \\
4.11^{\mathrm{a}}\end{array}$ & $\begin{array}{r}-0.48^{\mathrm{c}} \\
0.55^{\mathrm{b}} \\
0.92^{\mathrm{b}}\end{array}$ & $\begin{array}{c}-26.2^{\mathrm{c}} \\
-10.2^{\mathrm{c}} \\
5.1\end{array}$ \\
\hline $\mathrm{K}$ & $\begin{aligned} & 0.18^{\mathrm{c}} \\
&-0.10 \\
&-0.41^{\mathrm{a}}\end{aligned}$ & $\begin{array}{l}-1.03^{\mathrm{c}} \\
-2.98^{\mathrm{b}} \\
-3.18^{\mathrm{a}}\end{array}$ & $\begin{array}{l}-2.02^{\mathrm{a}} \\
-1.75^{\mathrm{a}} \\
-1.20^{\mathrm{a}}\end{array}$ & $\begin{array}{l}-38.3^{\mathrm{b}} \\
-28.1^{\mathrm{a}} \\
-16.3^{\mathrm{a}}\end{array}$ \\
\hline M & $\begin{array}{l}-0.28^{\mathrm{c}} \\
-0.55^{\mathrm{c}} \\
-0.64^{\mathrm{b}}\end{array}$ & $\begin{array}{r}0.41^{\mathrm{c}} \\
-2.75^{\mathrm{b}} \\
-3.82^{\mathrm{a}}\end{array}$ & $\begin{array}{c}0.19 \\
-0.84^{\mathrm{b}} \\
-0.96^{\mathrm{a}}\end{array}$ & $\begin{array}{l}21.5^{\mathrm{b}} \\
-4.9^{-9} \\
-8.0^{\mathrm{b}}\end{array}$ \\
\hline
\end{tabular}

${ }^{\text {a }}$ Significant at $1 \%$ level.

b Significant at $5 \%$ level.

c Significant at $10 \%$ level.

where $S(t)=\sum_{1}^{k} A_{i} \operatorname{Cos}\left(\omega_{i} t+\varphi_{i}\right)$ is the multiharmonic seasonal cycle presented by $k$ harmonics with divisible periods (12, 6, 4, 3, 2.4, and 2 months), amplitudes $A_{i}$, and phases $\varphi_{i} ; F(t)$ is the long-term year to year change; and $\epsilon(t)$ is short-period month to month variability, which is suggested to be a stationary random process. A similar approach to decomposing climatic time series has been used by Leith (1973) and by Mobley and Preisendorfer (1985). The long-term components $F(t)$ obtained were used for the study of interannual variability (trends, oscillations, etc.). We will give trends together with levels of significance estimated from a $t$ test for the number of degrees of freedom, which result from the number of independent values connected with the low-pass filter parameters (Bendat and Piersol 1966; Draper and Smith 1981; Hayashi 1982; Woodward and Gray 1993).

Table 2 presents the trends of SSTDs of different characteristics for 8 OWSs for observational periods shown in Table 1 . OWSs $\mathrm{L}$ and $\mathrm{R}$ were excluded from the analysis of long-term changes due to limited periods of observations (12 and $8 \mathrm{yr}$, respectively), which have very short overlaps with the time series at other locations (Table 1). OWS I, which contains the data starting from 1955, is also not shown in Table 2. Results for OWS $\mathrm{C}$ should be considered in the context of the ho- 
TABLE 3. Trends $\left(10^{-2} \mathrm{mb} \mathrm{yr}^{-1}\right)$ of SLP SSTD computed between each of the first $5 \mathrm{yr}$ and each of the last $5 \mathrm{yr}$ for OWSs D and J.

\begin{tabular}{cccccc}
\hline \hline \multicolumn{5}{c}{ OWS D, $\tau=3 \mathrm{~h}$} \\
& 1968 & 1969 & 1970 & 1971 & 1972 \\
\hline 1950 & 1.31 & 1.55 & 1.63 & 1.56 & $1.86^{\mathrm{c}}$ \\
1951 & -0.28 & -0.13 & 0.86 & 0.55 & 0.64 \\
1952 & $-2.83^{\mathrm{c}}$ & $-1.74^{\mathrm{c}}$ & -1.29 & -0.82 & -0.54 \\
1953 & $-5.69^{\mathrm{b}}$ & $-3.86^{\mathrm{b}}$ & $-2.62^{\mathrm{b}}$ & $-1.87^{\mathrm{c}}$ & $-2.08^{\mathrm{c}}$ \\
1954 & $-5.32^{\mathrm{b}}$ & $-3.23^{\mathrm{b}}$ & $-1.91^{\mathrm{c}}$ & $-2.15^{\mathrm{c}}$ & $-2.37^{\mathrm{b}}$ \\
\multicolumn{5}{c}{} \\
& OWS J, $\tau=3 \mathrm{~h}$ \\
1949 & $-1.76^{\mathrm{c}}$ & -0.94 & $-2.10^{\mathrm{c}}$ & $-2.77^{\mathrm{b}}$ & $-2.19^{\mathrm{c}}$ \\
1950 & $-2.68^{\mathrm{c}}$ & $-2.00^{\mathrm{c}}$ & $-3.57^{\mathrm{b}}$ & $-4.21^{\mathrm{b}}$ & $-3.63^{\mathrm{b}}$ \\
1951 & $-4.03^{\mathrm{b}}$ & $-3.13^{\mathrm{a}}$ & $-4.75^{\mathrm{b}}$ & $-5.33^{\mathrm{a}}$ & $-4.56^{\mathrm{b}}$ \\
1952 & $-7.25^{\mathrm{a}}$ & $-5.87^{\mathrm{a}}$ & $-7.36^{\mathrm{a}}$ & $-7.72^{\mathrm{a}}$ & $-6.64^{\mathrm{a}}$ \\
1953 & $-9.47^{\mathrm{a}}$ & $-7.64^{\mathrm{a}}$ & $-9.09^{\mathrm{a}}$ & $-9.31^{\mathrm{a}}$ & $-7.94^{\mathrm{a}}$ \\
\hline
\end{tabular}

a Significant at $1 \%$ level.

${ }^{\mathrm{b}}$ Significant at $5 \%$ level.

'Significant at $10 \%$ level.

mogeneity of records due to the occupation of OWS C by Soviet research vessels starting in July 1975 (Isemer 1994; Isemer and Lindau 1997, submitted to J. Atmos. Oceanic Technol.). Both mean values and statistics of a number of parameters for these two periods appear to be different from each other due to the systematic shift between U.S. and former Soviet Union observations (Isemer 1994). Thus, in the Table 2 we give the results for the period 1948-73, which coincides with other OWSs.

Table 2 shows that statistically significant changes of intramonthly standard deviations do exist. Taking into account the fixed positions, the homogeneity of the number of observations, and the relatively high accuracy of measurements (Isemer and Lindau 1997, submitted to J. Atmos. Oceanic Technol.), we can eliminate doubts about inadequate sampling influencing the results. For most of the parameters, SSTDs calculated from sampled observations have a general tendency to decrease with time for the midlatitude OWSs (those located in the vicinity of the North Atlantic storm track). Intramonthly standard deviations of wind speed and energy fluxes indicate these downward changes most clearly. SSTDs of SLP indicate downward tendencies of a lower significance and even show positive changes at OWS D. This can be explained by the influence of a 3-yr period around 1950, which indicates very low SSTDs of SLP. If we consider trends between each of the first $5 \mathrm{yr}$ and each of the last $5 \mathrm{yr}$ (Table 3), there will be significantly negative trends from the 1950s to the early 1970s. Thus, the integrated intramonthly variability resulting from the joint effect of the variations of the background flow, synoptic-scale fluctuations, and subsynoptic high-frequency variability becomes weaker during the 1950s, 1960s, and early 1970s over the North Atlantic midlatitudes. The opposite tendency (positive trends of sampling SSTD is detected for OWSs E and M, which are located either in the subtropics, south of the main North Atlantic storm track (OWS E), or in the high latitudes (OWS M), where synoptic variability is determined by already strongly degraded midlatitude cyclones and by the polar lows. OWSs $\mathrm{A}$ and $\mathrm{K}$ indicate positive trends in SSTD of only air temperature.

Increasing the period of previous averaging $(\tau)$ has the effect of filtering out short-term variability with temporal scales of less than $\tau$ from the sampled data. Thus, SSTDs computed for different $\tau$ account for the variability of different synoptic and subsynoptic scales. Timescales of 2-6 days are associated with the extratropical cyclones that quite clearly identify the North Atlantic storm track (Robertson and Metz 1990; Ayrault et al. 1995; Branstator 1995; Hurrell 1995a). Relatively low-frequency variability for timescales larger than 10 days is connected with changes in weather regimes, which are associated with the so-called zonal and blocking regimes (Charney and de Vore 1979; Branstator 1992). The short-term fluctuations for periods smaller than 1.5 days contribute to the so-called ultra-high-frequency variability (Blackmon et al. 1984; Ayrault et al. 1995). The most remarkable changes in SSTD trends appear in the northeast Atlantic midlatitudes as $\tau$ increases from 48 to $72 \mathrm{~h}$ and from $120-180$ to $240 \mathrm{~h}$. For most of the midlatitude OWSs, negative trends of SSTD significantly decrease with $\tau$. At OWSs A, C, and $\mathrm{J}$, negative trends of SSTD tend to become positive. Thus, short-term synoptic and subsynoptic variability had a tendency of weakening during the 1950s and 1960 s, with a simultaneous strengthening of variability for timescales larger than 5-7 days.

A number of parameters indicate changes of the polynomial fitting (Fig. 2). If we consider the 1950s and the early 1960s at OWS J, there is a negative trend of the SSTD of air temperature ranging from $-0.13^{\circ}(10 \mathrm{yr})^{-1}$ to $-0.19^{\circ}(10 \mathrm{yr})^{-1}$ for $\tau=3 \mathrm{~h}$, and there is a positive trend close to $0.2^{\circ}(10 \mathrm{yr})^{-1}$ for $\tau>5$ days. As a result, the second-order curve of the SSTD of $T_{a}$ changes to the third order. At OWS A the linear trend of momentum flux SSTD for $3<\tau<24$ h becomes a second-order polynomial for $\tau>72 \mathrm{~h}$ due to the sharp decrease of SSTD in the mid-1950s (Fig. 2). This character of the long-term variability (second-order polynomial) remains generally unchanged up to $\tau=240 \mathrm{~h}$. For OWSs $\mathrm{E}, \mathrm{M}$, and partially $\mathrm{K}$, positive trends obtained for small $\tau$ appear to become negative with $\tau$. Thus, OWS K shows a significant positive trend in SSTD for sampled observations of air temperature and humidity and a significantly negative trend for $\tau>120 \mathrm{~h}$ (Table 2). Figure 3 demonstrates how the structure of year to year variations changes with $\tau$ at OWS M. Remarkably, the wind speed SSTDs during the late 1960s, 1970s, and 1980s demonstrate an increase in $\tau$ close to the sampling period and a downward tendency at $\tau>72 \mathrm{~h}$.

To study the interannual variability within the range of several years, the empirical orthogonal functions (EOF) analysis was applied to the detrended series of 

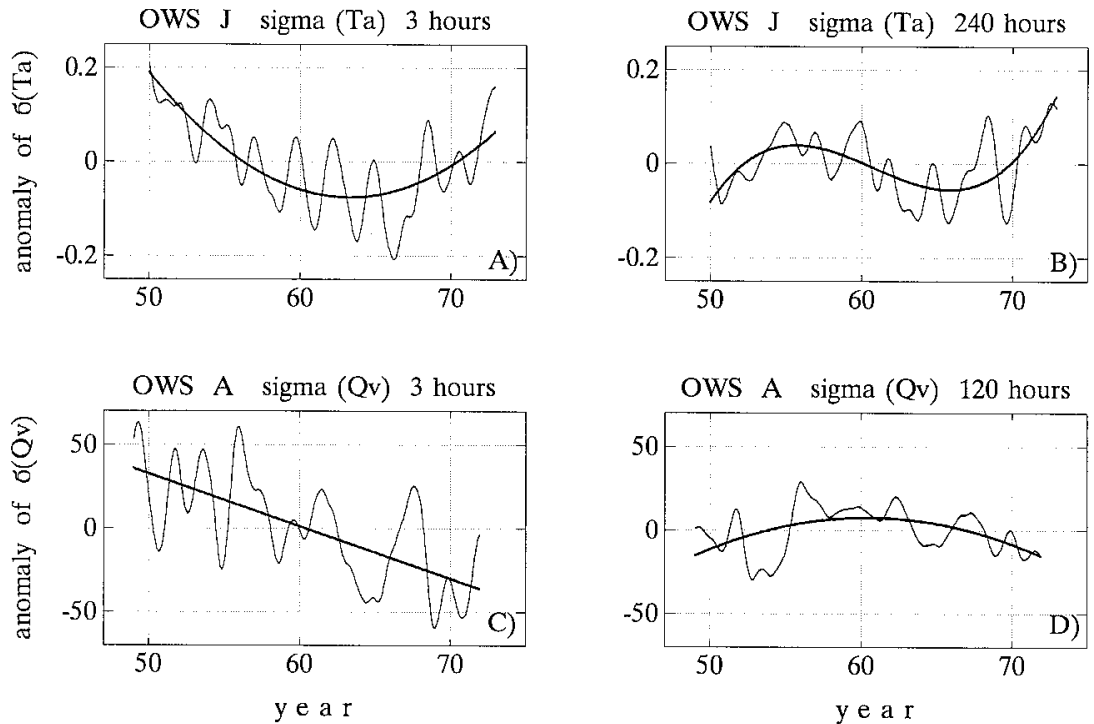

FIG. 2. Long-term variability of SSTD of air temperature, (a) calculated from sampled observations and (b) as previously averaged with $\tau=240$-h observations at OWS J. Longterm variability of momentum flux SSTD, (c) computed for sampled data and (d) as averaged with $\tau=120 \mathrm{~h}$ data at OWS A.

the long-term anomalies of SSTD. To ensure that EOFs calculated from the North Atlantic OWS indicate patterns known from the other studies based on gridded climatologies (e.g., COADS), we calculated the first EOFs of monthly anomalies of SST and SLP that could be compared with a number of results (Weare 1977; Wallace et al. 1990; Zorita et al. 1992; Cayan 1992b,c), although it is difficult to compare in detail EOFs computed from different domains and periods. Figure 4 shows the first two EOFs of SST anomalies. The first EOF, which accounts for $38 \%$ of variance, indicates a structure that is very similar to those obtained by Wallace et al. (1990) and Zorita et al. (1992) on the basis of COADS SSTs, averaged onto a $4^{\circ}$ lat $\times 10^{\circ}$ long grid. The second EOF ( $22 \%$ of variance) is also com-

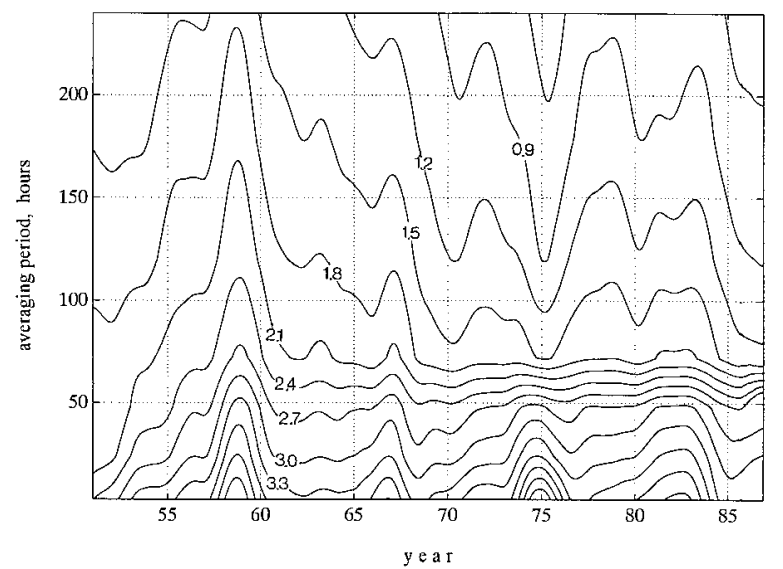

FIG. 3. Long-term changes of wind speed $\mathrm{m} \mathrm{s}^{-1}$ SSTD at OWS M for different periods of previous averaging. parable with the previous studies and demonstrates positive values in the North Atlantic midlatitudes. Thus, the OWS locations provide, at least, the qualitatively realistic patterns of variability that are important for the future consideration of intramonthly statistics. Table 4 displays variances explained by the first three EOFs for
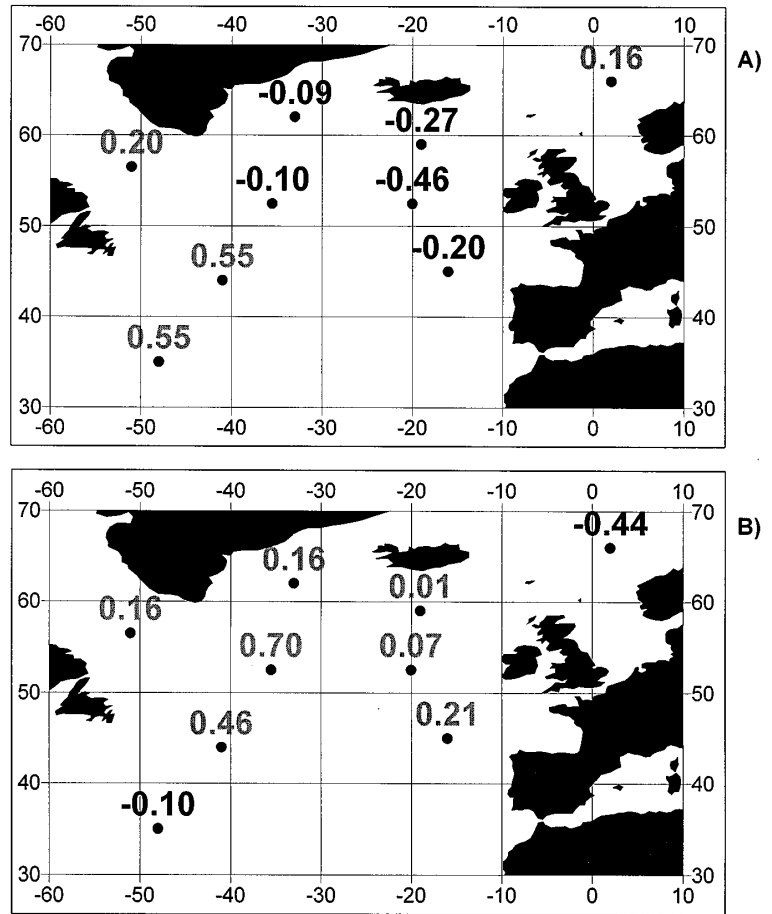

FIG. 4. (a) First and (b) second EOFs of monthly mean sea surface temperature at 9 North Atlantic OWSs. 
TABLE 4 . Monthly anomaly variance explained (in percent) by the first three EOFs for SSTDs of different parameters.

\begin{tabular}{lcrrrc}
\hline \hline & & \multicolumn{4}{c}{ Averaging period, hours } \\
\cline { 3 - 6 } \multicolumn{1}{c}{ sstd } & EOF & 3 & 72 & 120 & 240 \\
\hline \multirow{3}{*}{ SLP } & 1 & 40 & 40 & 37 & 31 \\
& 2 & 18 & 17 & 18 & 23 \\
& 3 & 10 & 13 & 15 & 14 \\
$T_{a}$ & 1 & 34 & 32 & 30 & 29 \\
& 2 & 20 & 21 & 22 & 28 \\
& 3 & 16 & 14 & 15 & 12 \\
$V$ & 1 & 31 & 31 & 32 & 35 \\
& 2 & 22 & 20 & 19 & 15 \\
& 3 & 12 & 15 & 16 & 12 \\
$V_{x}$ & 1 & 26 & 33 & 37 & 38 \\
& 2 & 25 & 25 & 24 & 22 \\
& 3 & 14 & 14 & 12 & 12 \\
$Q_{H}+Q_{E}$ & 1 & 44 & 47 & 49 & 50 \\
& 2 & 24 & 19 & 19 & 17 \\
\multirow{3}{*}{$Q_{v}$} & 3 & 8 & 10 & 11 & 13 \\
& 1 & 31 & 31 & 33 & 34 \\
& 2 & 27 & 24 & 23 & 21 \\
& 3 & 13 & 12 & 11 & 13 \\
\hline
\end{tabular}

SSTDs of different parameters for different averaging periods. Together, the first two EOFs account for 50\% to $70 \%$ of the variance for different SSTDs. For SLP and air temperature, the percentage of contribution from the first EOF decreases with the averaging period and the contribution from the second EOF grows up si- multaneously. For the wind speed and its components and fluxes, there is an opposite tendency. The relative contribution from the first EOF increases with $\tau$, and variance explained by the second EOF becomes smaller for large $\tau$. Figures 5-7 show changes in EOFs of SSTD computed for different averaging periods for selected variables. Usually EOFs of SSTD calculated for $\tau<24$ $\mathrm{h}$ are comparable to each other. Visible changes occur (if at all) when $\tau=72 \mathrm{~h}$ and become quite pronounced for $\tau=120 \mathrm{~h}$.

The first two EOFs of the SSTD of SLP for $\tau=3 \mathrm{~h}$ and $\tau=120 \mathrm{~h}$ are shown in Fig. 5. Note that the spatial structures of the EOFs computed for the sampled data are similar to those obtained by Zorita et al. (1992) on the basis of COADS intramonthly standard deviations. The first EOF is positive everywhere, with a maximum in the east Atlantic midlatitudes, (OWSs J and K). The second EOF indicates a dipole structure, with negative values at OWSs $\mathrm{J}$ and $\mathrm{K}$. For larger $\tau$, both EOFs of SLP SSTD are not changed significantly, except for at OWS B, where the sign of the second EOF is changed from positive to negative. The first EOF of scalar wind SSTD, calculated for $\tau=3 \mathrm{~h}$, is significantly positive in the west Atlantic (OWSs C, D, and E) and weakly negative in the east Atlantic (OWSs I, J, and K) midlatitudes (Fig. 6). Alternatively, in the high latitudes associated with polar lows, the first EOF of sampled scalar wind SSTD indicates negative values in the western parts of OWSs A and B, and a large positive value
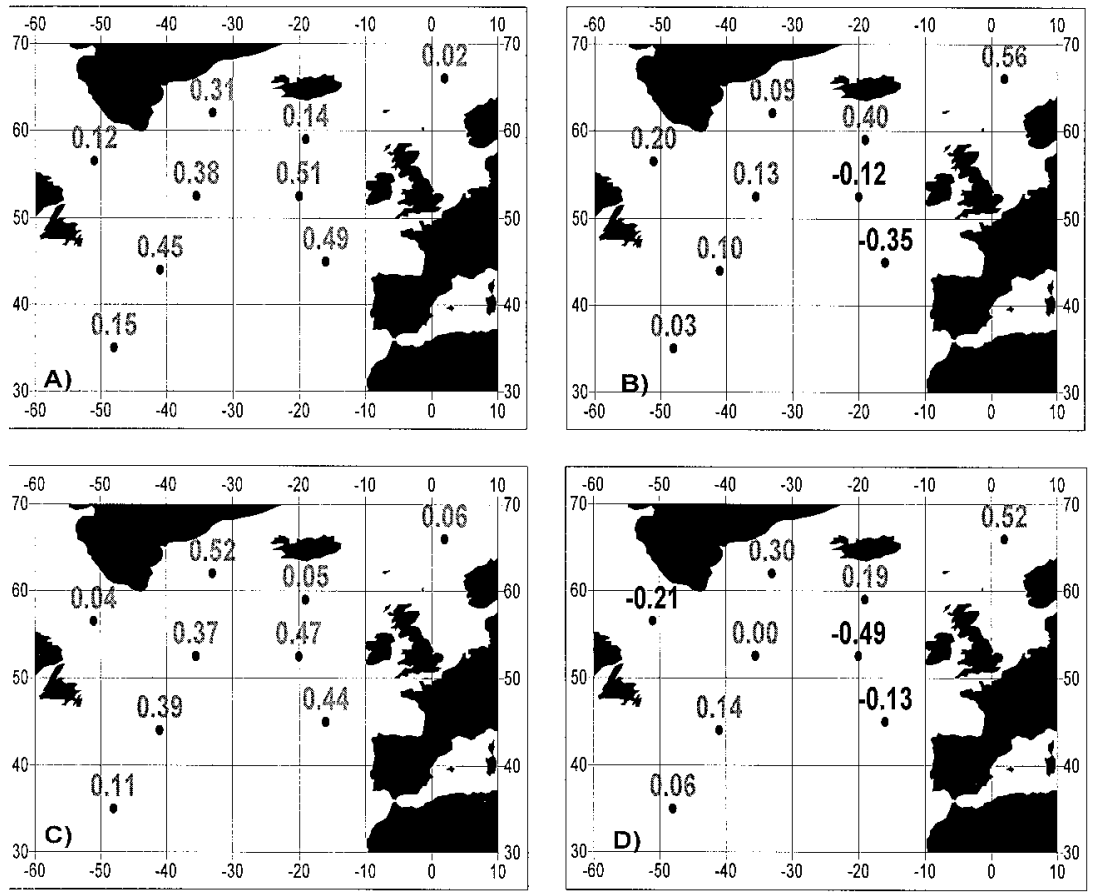

FIG. 5. (a) and (c) First and (b) and (d) second EOFs of SLP (SSTD), (a) and (b) computed from sampled and (c) and (d) as previously averaged with $\tau=120 \mathrm{~h}$ data at 9 North Atlantic OWSs. 

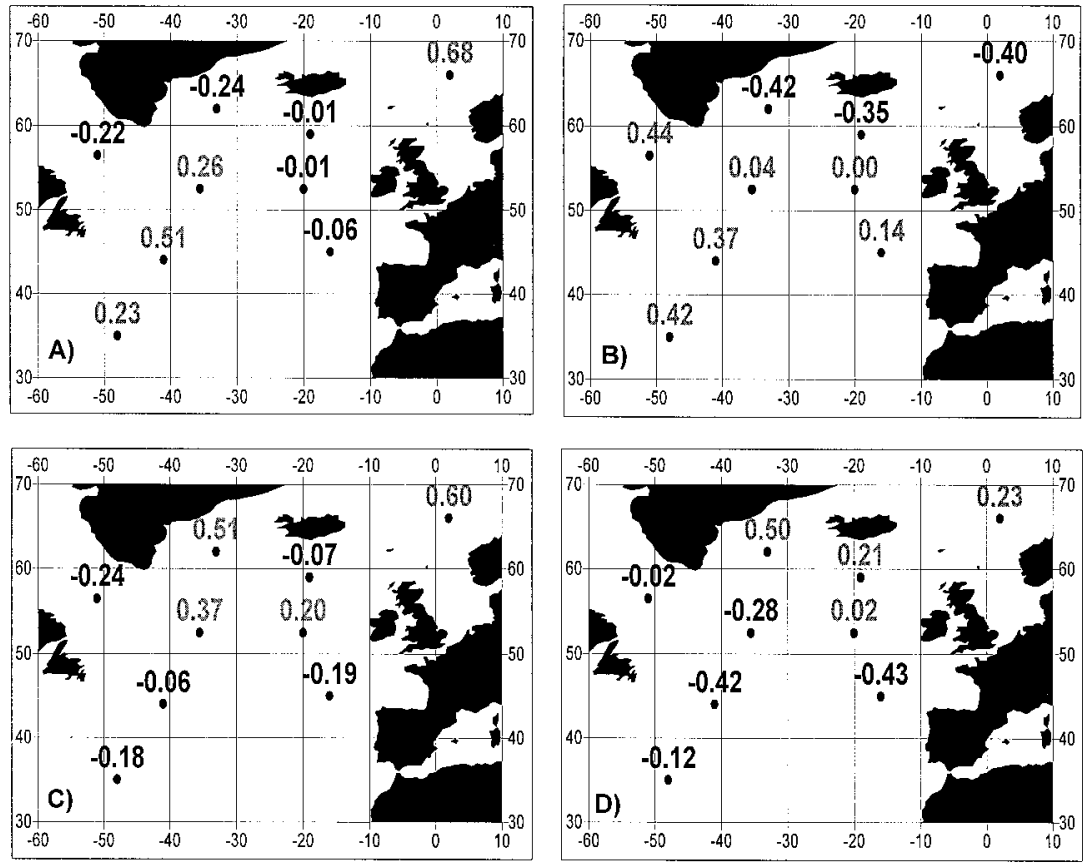

FIG. 6. (a) and (c) First and (b) and (d) second EOFs of scalar wind speed SSTD, (a) and (b) computed from sampled and (c) and (d) as previously averaged with $\tau=120 \mathrm{~h}$ data at 9 North Atlantic OWSs

at OWS M. If $\tau$ increases up to $120 \mathrm{~h}$, the first EOF of wind speed SSTD indicates negative values south of $50^{\circ} \mathrm{N}$ and at OWS $\mathrm{B}$, and primarily positive values in the central and the northeast Atlantic (OWSs A, C, and $\mathrm{J})$, associated with alternating blocking and zonal regimes. The second EOF of scalar wind SSTD exhibits a dipole structure, with centers of action located in the west Atlantic midlatitudes and in the northeast Atlantic. For the sampled data $(\tau=3 \mathrm{~h})$ these centers are associated with large positive values at OWSs B, D, and E, and significantly negative values at OWSs A, I, and M. For $\tau>72 \mathrm{~h}$ there is an opposite tendency: negative values appear in the western midlatitudes (OWSs B, C, $\mathrm{D}$, and $\mathrm{E}$ ), and positive ones appear in the high latitudes. Temporal averaging also significantly changes the spatial structure of the first two EOFs of the SSTD of sensible and latent heat fluxes (Fig. 7). For small $\tau$ significantly negative values of the first EOF are observed only at the location of OWS A. For larger $\tau$ the first EOF is negative at OWSs A, B, C, and D, located in the northwest Atlantic. The second EOF of the SSTD of sensible and latent fluxes for sampled data indicates a dipole structure, with the zero line at approximately $50^{\circ} \mathrm{N}$. With the increase of $\tau$, zonal dipole patterns are replaced by the meridional dipole structure, with positive values in the west Atlantic midlatitudes and remarkably negative values at the east Atlantic OWSs.

Interannual variability of EOFs of SSTD is quite different for different periods of temporal averaging. SSTDs of SLP indicate less pronounced changes in the patterns of interannual variability with increasing $\tau$ than other parameters. Figure 8 shows, as an example, the interannual variations of the first two EOFs of air temperature SSTD, computed for different $\tau$, and Fig. 9 represents the spectra of SSTD EOFs for scalar wind speed. Figures 8 and 9 demonstrate remarkable changes of spectral structure of variability for the first two EOFs of SSTD. For the first EOF, spectral peaks have a tendency to shift from smaller periods to larger periods with the increase of $\tau$. When $\tau$ is small enough, the interannual variability of the first EOF is characterized by $2-2.5-y r$ oscillations. For relatively large $\tau$, interannual variability is mostly represented by $3.8-4.5-\mathrm{yr}$ oscillations. Alternatively, the second EOF for most parameters demonstrates an opposite tendency with $\tau$. Intramonthly SSTDs calculated from sampling data are characterized by weak 36-42-month oscillations, in contrast with those calculated from previously averaged data, which indicate $2-2.5-y r$ oscillations. Thus, the east-west dipole structure of the first EOF of SSTD of most parameters transforms significantly with the increase of $\tau$, and interannual oscillations grow to larger periods. For the second EOF, with the increase of $\tau$, south-north dipole structure transforms to east-west patterns and relatively long-period oscillations for small $\tau$ are replaced by pronounced, higher-frequency variations, with typical periods of 2-2.5 yr with increasing $\tau$.

\section{b. Relation of intramonthly statistics to the SST variability}

It is interesting to consider whether any relationships exist between the features of long-term variability of 

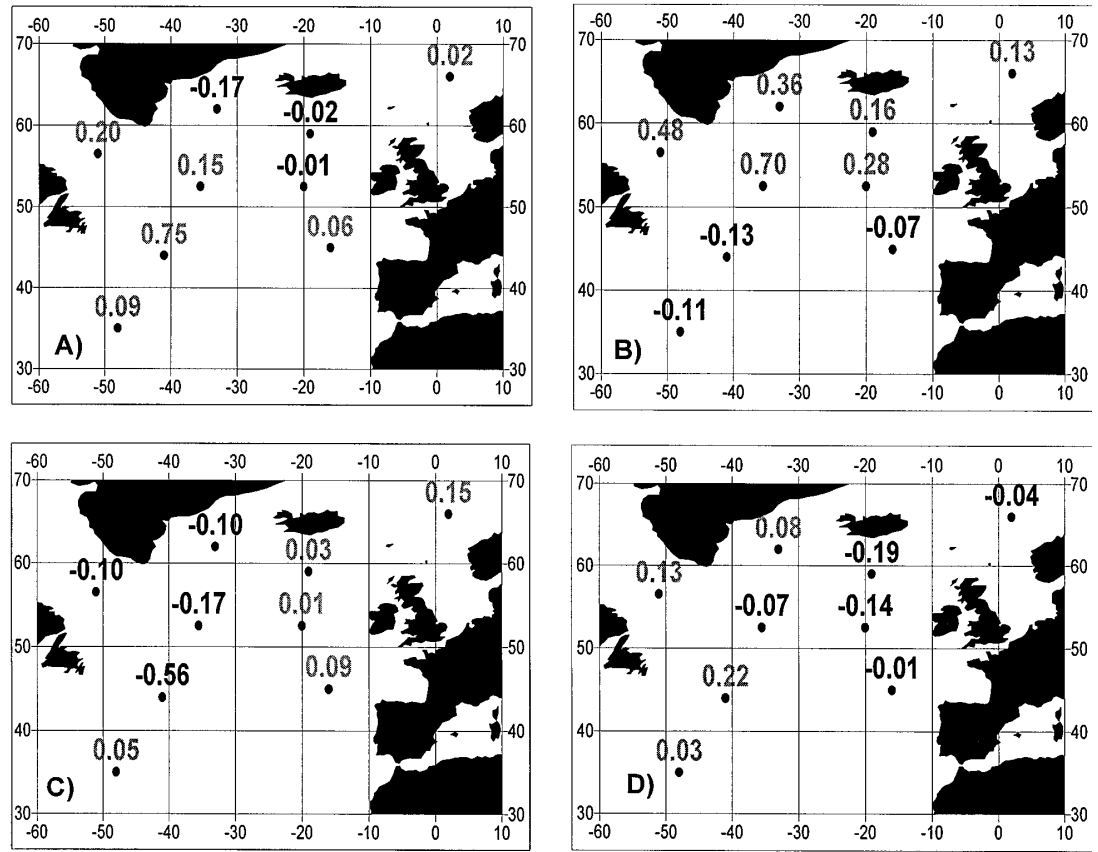

FIG. 7. (a) and (c) First and (b) and (d) second EOFs of sensible plus latent heat flux SSTD (a) and (b) computed from sampled and (c) and (d) as previously averaged with $\tau=120 \mathrm{~h}$ data at 9 North Atlantic OWSs.

SST and the intramonthly statistics. Most of the results dealing with the long-term changes of SST in the North Atlantic midlatitudes indicate statistically significant negative trends in the location of the North Atlantic OWSs for the respective time periods. For example, Bottomley et al. (1990) have found in the east midlatitude North Atlantic (their box includes OWSs I, J, and
K) negative SST changes of about $0.2^{\circ} / 10$ yr for the period 1949-72. This is also supported by the extensive consideration of SST trends taken by Oort et al. (1987). Studies of short-term interannual variations of SST (Frankignoul and Hasselmann 1977; Frankignoul 1985) showed the flattening of the red spectra of SST anomalies at periods of about several years. In a number of
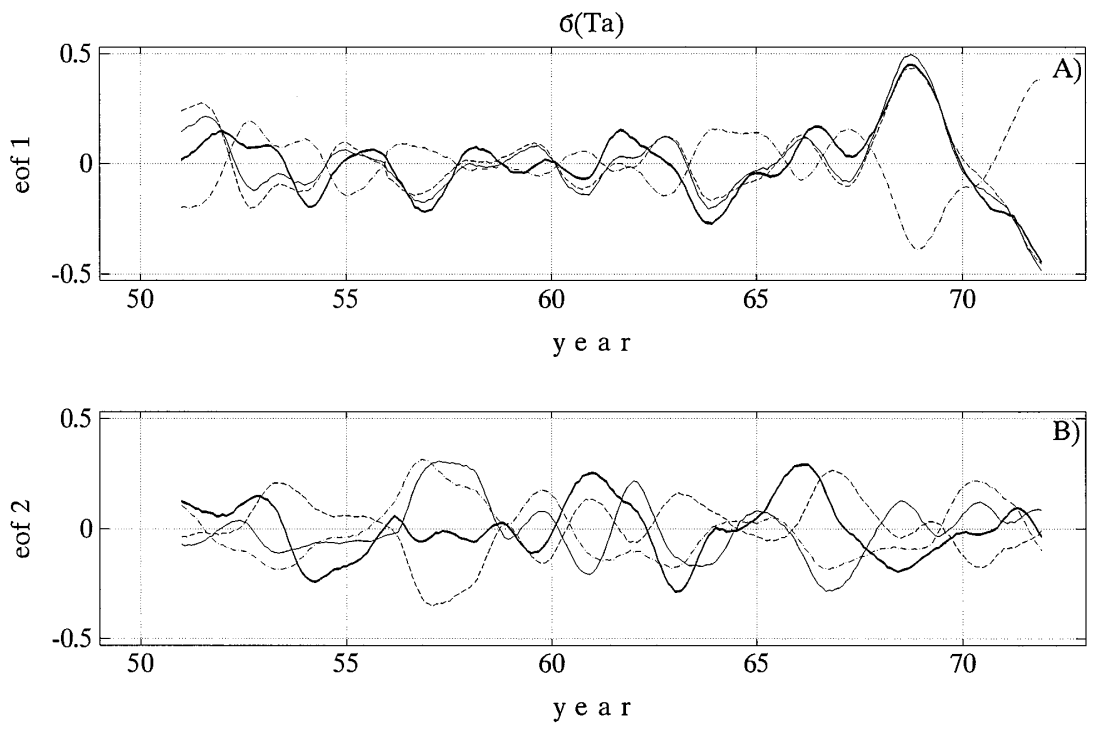

FIG. 8. Time series of the (a) first and (b) second EOFs of air temperature SSTD, computed for $\tau=3 \mathrm{~h}$ (bold line), $\tau=72 \mathrm{~h}$ (thin line), $\tau=120 \mathrm{~h}$ (dashed line), and $\tau=240 \mathrm{~h}$ (dashdot line). 

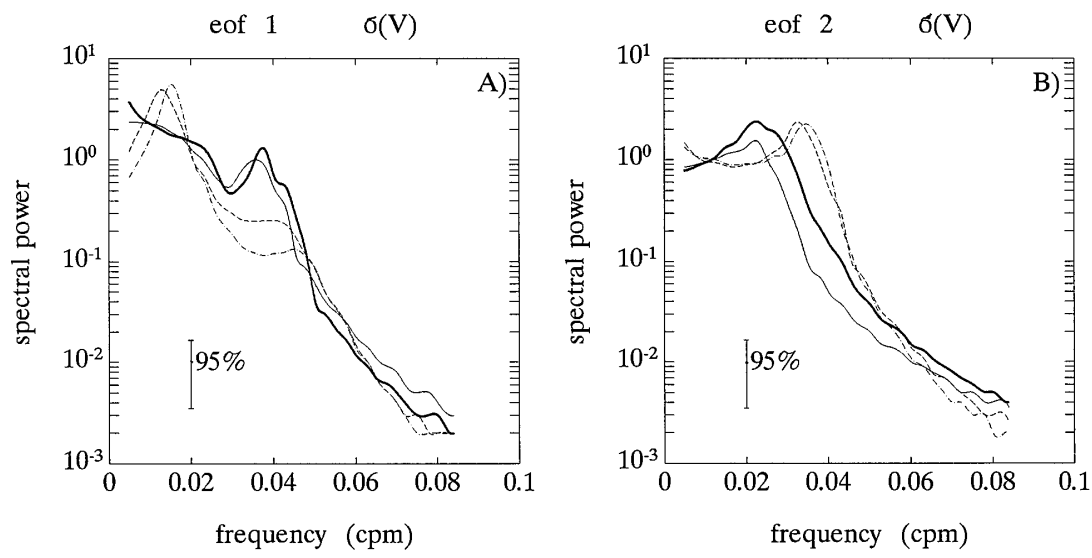

FIG. 9. Spectra of the (a) first and (b) second EOFs of scalar wind speed SSTD, computed for $\tau=3 \mathrm{~h}$ (bold line), $\tau=72 \mathrm{~h}$ (thin line), $\tau=120 \mathrm{~h}$ (dashed line), and $\tau=240 \mathrm{~h}$ (dashdot line).

articles (Elsberry and Camp 1978; Camp and Elsberry 1978; Elsberry and Garwood 1978; Daly 1978) the SST anomalies have been considered as a result of an atmospheric impact. Hasselmann (1976) and Frankignoul and Hasselmann (1977) proposed stochastic models where SST anomalies are driven by uncorrelated white noise atmospheric forcing. Later works (Blaauboer et al. 1982; Frankignoul and Reynolds 1983; Frankignoul 1985; Herterich and Hasselmann 1987; Hannoschock and Frankignoul 1985) have developed such models and applied them to different basins and different data. Atmospheric forcing in such models is usually represented by air-sea heat fluxes, the contribution from anomalous wind stress, and the effects of mixed layer depth variability. Recently Alexander and Deser (1995) found evidence of the so-called reemergence mechanism of wintertime SST anomalies, proposed first by Namias and Born (1970). Most studies have considered monthly means of surface variables to describe atmospheric forcing. SST reaction has been found to be 1 month lagged in relation to this forcing, although synoptic-scale studies (e.g., Elsberry and Camp 1978) have found that at least surface heat fluxes and wind stress lead the SST, primarily by 2 to 3 weeks. Zorita et al. (1992) and von Storch et al. (1993) suggested that intramonthly SSTD of SLP can also be considered as possible agents of SST changes, assuming that anomalous intensification of cyclonic activity, reasonably associated with higher fluxes and wind stress, leads by several weeks the cooling of the ocean mixed layer. Using the COADS intramonthly SSTD of SLP for $2^{\circ} \times 2^{\circ}$ boxes, Zorita et al. (1992) found $\sigma_{\mathrm{SLP}}$-SST 1-month-lagged correlations to be significant for winter months.

Intramonthly statistics of forcing parameters account for both forcing frequency and forcing magnitude. On the other hand, SSTDs of different parameters computed for different averaging periods make it possible to consider the role of different synoptic scales driving the long-term SST anomalies. To calculate the correlation between SSTDs of different parameters and SST anomalies we have used the first 2 EOFs of long-term variations of SST and respective SSTDs for every $\tau$. These EOFs explain $60 \%$ of the total variance of SST and from $50 \%$ to $70 \%$ of SSTD variances for different parameters and different averaging scales (Table 4). For example, Zorita et al. (1992) used the first 5 EOFs to get a higher percentage of the total variance explained. Cayan (1992c) truncated 8 and 12 EOFs of the forcing fields and SST tendency anomalies, respectively. At the same time these works used arrays of higher dimensions, which reasonably assume that more leading EOFs are taken. To ensure that the truncation used is effective, we repeated the calculations using the first 3 and 5 EOFs, which usually explain at least $75 \%$ and $90 \%$ of the total variance. We got qualitatively matching results, although the correlation became weaker for a larger number of EOFs truncated.

Correlation functions between most SSTDs and SSTs are asymmetric and indicate maximal negative correlation, when the SSTD leads the SST by 1 month. This is generally consistent with the hypothesis that SST anomalies are driven by atmospheric forcing in the midlatitudes. At the same time the lagged correlation between SSTD and SST anomalies remarkably depends on the averaging scale that the SSTD is computed for. Figure 10 shows 1-month-lagged correlation behavior with $\tau$ for SLP SSTD and scalar wind speed. The latter is considered to be the most active agent of atmospheric forcing, being responsible for the anomalous wind stress and partially for the surface heat fluxes. Correlations were computed for winter (December-March) and summer (June-September) months. The highest negative lagged correlations between SLP SSTD was obtained for $\tau=48 \mathrm{~h}$ in winter and for $\tau=120 \mathrm{~h}$ in summer. If we consider the correlation between the SSTD of scalar wind and SST, there will be a weakening tendency of the correlation with increasing $\tau$ for wintertime. For the averaging scale of $180 \mathrm{~h}$, correlation even becomes 

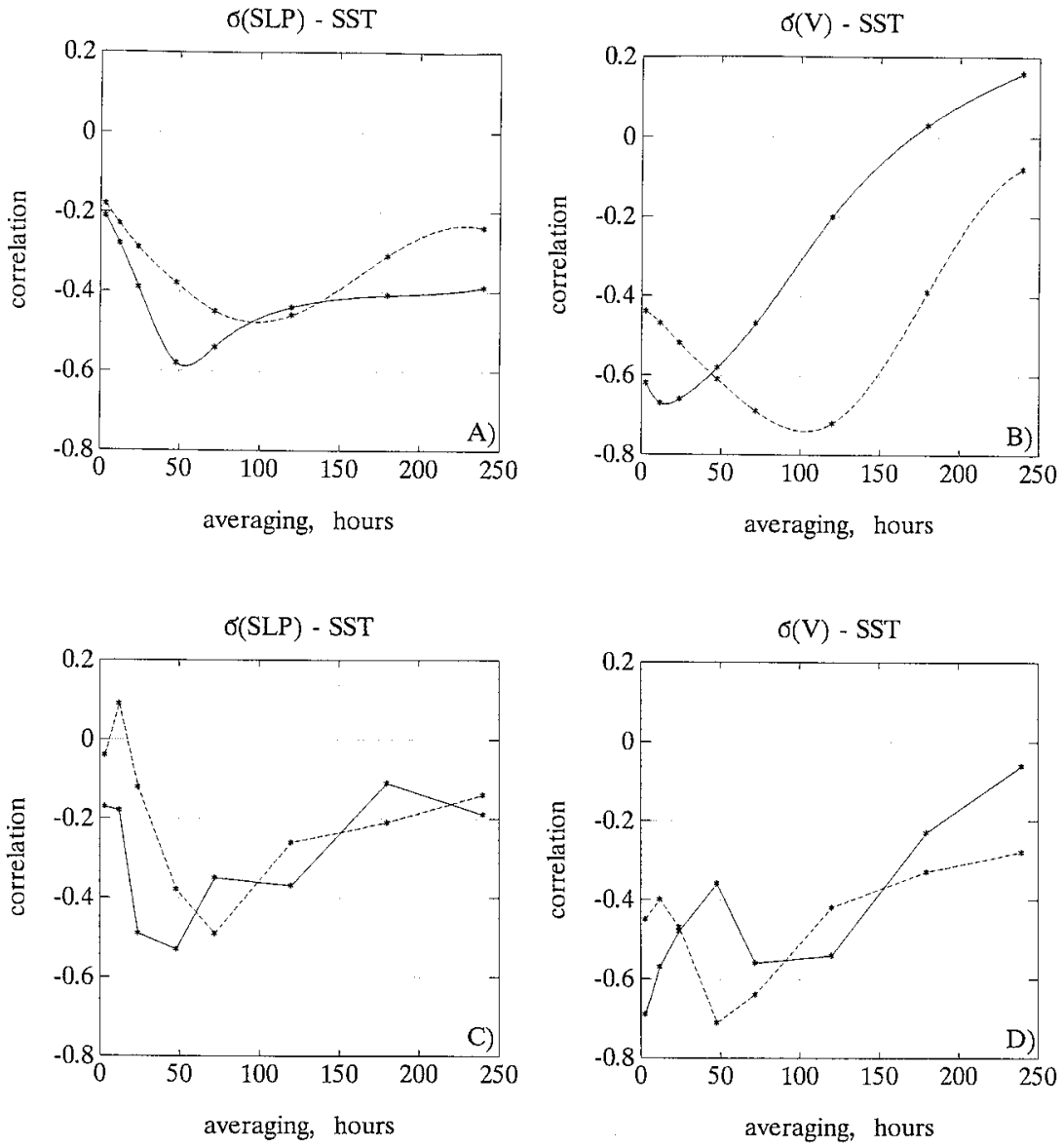

FIG. 10. The behavior with $\tau$ of 1-month-lagged correlation between (a) the first two EOFs of the SSTDs of SLP and SST anomalies and (b) the first two EOFs of the SSTDs of scalar wind speed and SST anomalies for winter (solid line) and summer (dashed line) months. (c) and (d) Results for OWSs D and J, respectively, in the same manner as in (a) and (b). The level of $95 \%$ significance is equal to 0.436 .

positive, although the coefficients underpredict the level of significance. The highest negative correlation of -0.69 has been obtained for $\tau=12 \mathrm{~h}$. Alternatively, for the summer months the correlation maximum is observed at $\tau=120 \mathrm{~h}$. Thus, short-period mesoscale variability with timescales of about several hours does not contribute significantly into midlatitude SST changes. Effective synoptic forcing of SST anomalies during wintertime is connected with relatively fast extratropical cyclones and ultra-high-frequency variability. In summer, the most remarkable negative 1-month-lagged correlations are observed for the synoptic variability with typical scales of about 5 days, which is associated with either slow developing cyclones or with changes in the background flow regimes. If we consider individual OWSs, there will be general similarity, although some differences appear between the western and the eastern parts of the North Atlantic midlatitudes. Figures 10c,d show 1-month-lagged winter correlations for OWSs D and $\mathbf{J}$ in the same manner as Figs. 10a,b. The highest negative correlation in the west Atlantic is observed for smaller averaging periods than in the east Atlantic. Wind speed at OWS D (Fig. 10d) indicates two maxima at $\tau$ $=3 \mathrm{~h}$ and $\tau=72 \mathrm{~h}$. This is consistent with the differences in timescales of synoptic variability in the western and eastern Atlantic midlatitudes. In the west Atlantic synoptic-scale cyclones and subsynoptic cyclones responsible for the ultra-high-frequency variability appear during both zonal and blocking regimes of the background flow (Ayrault et al. 1995). At the same time, in the eastern midlatitude Atlantic cyclones have larger temporal scales and are associated with zonal weather regimes only.

It is interesting to consider the forcing of SST anomalies by SSTD of sea-air heat fluxes, which results from the joint effect of the fluctuations of thermal and dynamic characteristics. Figure 11 shows the month to month correlation matrices between the first two EOFs of SSTD of the sensible plus latent heat fluxes $\sigma\left(Q_{H}+\right.$ $Q_{E}$ ) and the first two EOFs of SST anomalies. The correlations were computed for $\tau=12 \mathrm{~h}$ and $\tau=120 \mathrm{~h}$. Again, nearly all significant correlations are negative 


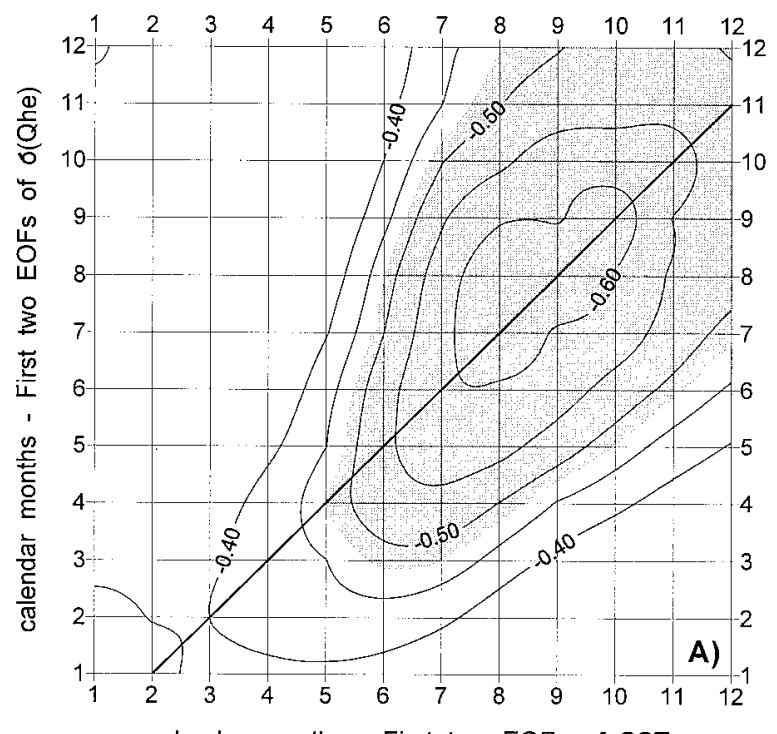

calendar months - First two EOFs of SST

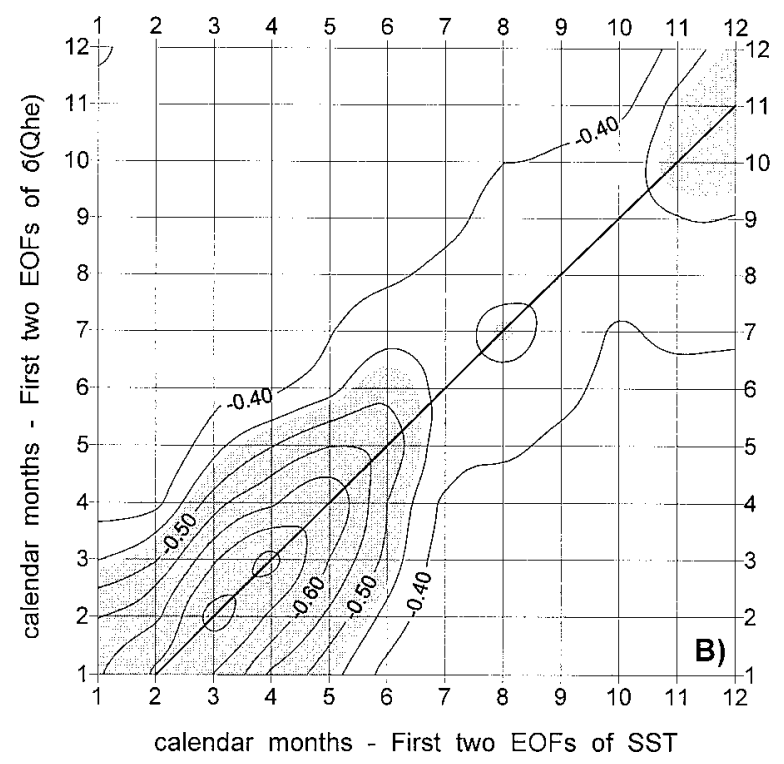

FIG. 11. Matrices of month to month correlation between the first two EOFs of SST anomalies and the first two EOFs of virtual heat flux $\left(Q_{H}+Q_{E}\right)$ SSTD, computed for (a) $\tau=12 \mathrm{~h}$ and (b) $\tau=120 \mathrm{~h}$ The level of $95 \%$ significance is equal to 0.479 . Isolines are plotted for $|r| \geq 0$.4. Diagonals correspond to the lag of 1 month.

and the strongest relationships observed when SSTD leads SST anomalies by 1 month. The highest SSTDs of fluxes are associated with increasing frequency of cyclones, which are mostly responsible for ocean heat losses through turbulent fluxes. Thus, the 1-monthlagged negative correlation obtained is consistent with the general idea that increased sea-air flux leads to decreasing temperature (i.e., Cayan 1992c) and with the hypothesis that the increase of the cyclonic activity (thus, higher SSTD of sea-air fluxes) will support the cooling of the mixed layer. There is evidence that the intensification of the cyclonic activity is associated with increasing turbulent fluxes in individual cyclones, connected with cold-air outbreaks in offshore regions and over midlatitude SST fronts (Yau and Jean 1989; Gulev and Tonkacheev 1994; Miller and Katsaros 1992). Synoptic forcing of SST anomalies by fluctuating sea-air heat flux is more effective in autumn for sampled SSTD and during spring for SSTD calculated from previously averaged series with $\tau=72-120 \mathrm{~h}$. The largest absolute values of the negative lagged correlation in Figs. 11a,b are observed in September-October for $\tau=12 \mathrm{~h}$ and in March for $\tau=120 \mathrm{~h}$, and are always higher than during purely winter months. Alexander and Deser (1995) noted the specific role of the winter-spring period for the creation of long-life SST anomalies, which may reappear then in the fall-winter season. Thus, during autumn, when the ocean mixed layer is still shallow and developing, the anomalous cooling is associated primarily with fast subsynoptic transients. In spring, when the mixed layer is deep, negative SST anomalies are forced by mostly well-developed synoptic-scale cyclones, which provide extremely high ocean-atmosphere fluxes.

\section{c. Intramonthly SSTD and the North Atlantic oscillation}

The NAO is associated with temperature differences between Greenland and northern Europe, driven by the North Atlantic meridional SLP gradient (van Loon and Rogers 1978; Lamb and Peppler 1987; Barnston and Livezey 1987; Hurrell 1995b). The SLP gradient between the normalized winter anomalies for the Azores high and Iceland low represents the NAO index (Rogers 1984), which is reasonably linked to the synoptic activity in the northeast Atlantic midlatitudes. Since the computed intramonthly statistics account for various scales of synoptic and subsynoptic variability, we assume them to be an effective indicator of the NAO extremes. Obtained downward tendencies in SSTD are consistent with the decrease of the NAO index from the late 1940 s to the early 1970 s (Hurrell 1995b). This period is characterized by a cyclonic anomaly of the mean circulation (Kushnir 1994), which is associated with remarkable shifts in the storm tracks and synoptic eddy activity (Hurrell 1995a). To consider the link between interannual SSTD variations and the NAO, we compared NAO indexes with OWS J SSTD, averaged over 3 winter months (December-February). Figure 12 shows significant correlation between the winter SSTD of air temperature computed for $\tau=12 \mathrm{~h}$ and the NAO indexes during 22 winters from 1952 to 1973 . Table 5 shows such correlation coefficients computed for the whole range of averaging periods.

If the NAO index increases (GB), the midlatitude zonal flow becomes more intensive and the number of relatively fast wave-type cyclones increases as well (Lamb and Peppler 1987; Carleton 1988). Note here that for this regime Ayrault et al. (1995) showed a consid- 

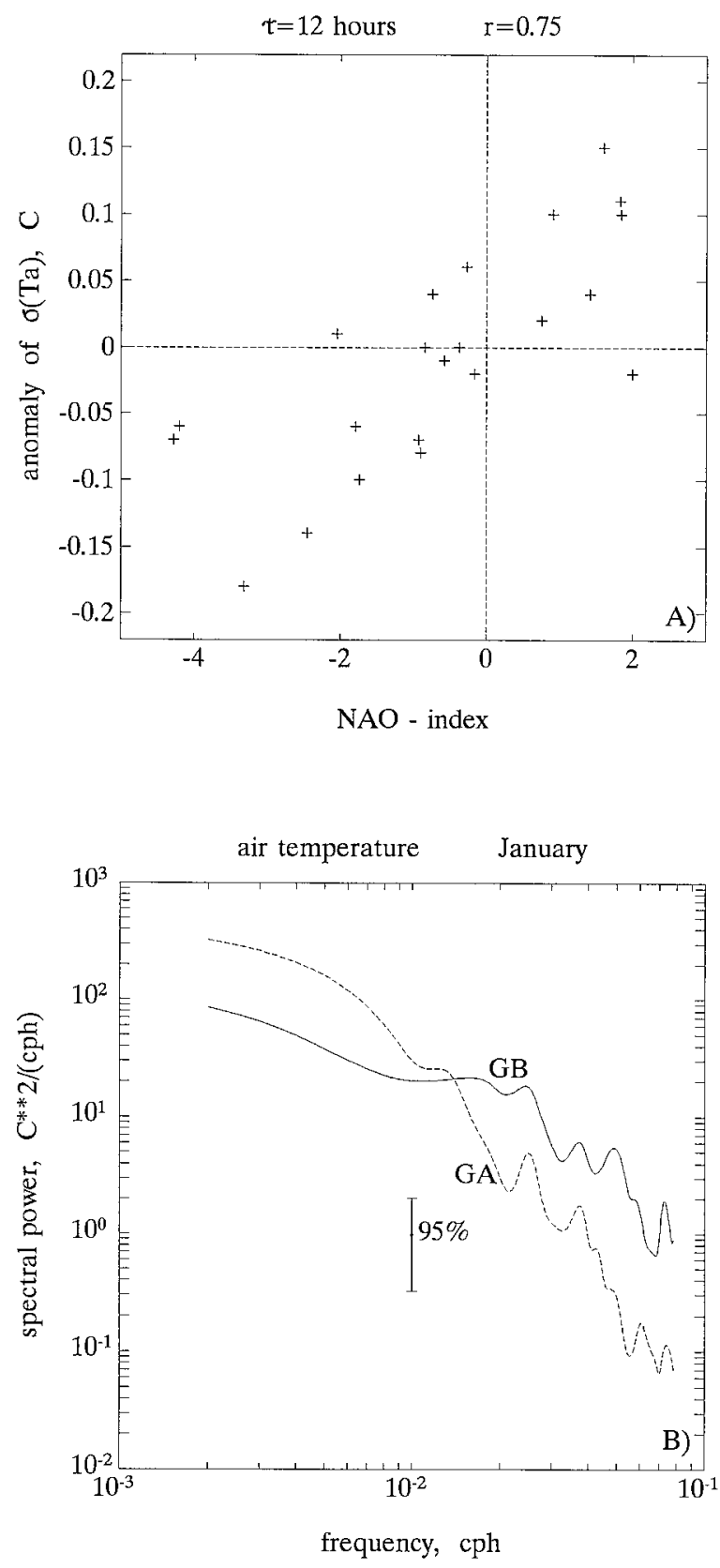

FIG. 12. Dependence of anomalies of air temperature SSTD $(\tau=$ $12 \mathrm{~h}$ ) on the NAO index for 22 winters from 1952 to 1973 at OWS $\mathrm{J}$, and January spectra of 3-h air temperature, averaged for 1970-73 (GB) and 1962-66 (GA).

erable increase of the number of subsynoptic cyclones that are responsible for the ultra-high-frequency variability in the east Atlantic. In the opposite case (GA) the number of slow stationary cyclones increases in the east Atlantic and the maximum of ultra-high-frequency subsynoptic variability appears in the west Atlantic midlatitudes. Thus, we expect increasing SSTD, computed from sampled (or averaged with small $\tau$ ) series, for GB and decreasing SSTD in the case of GA. Alternatively,
TABLE 5. Correlation coefficients between winter SSTDs of air temperature and wind speed computed for different $\tau$ at OWS J, and the NAO index.

\begin{tabular}{ccc}
\hline \hline$\tau$, hours & $\sigma\left(T_{a}\right)$ & $\sigma(V)$ \\
\hline 3 & 0.67 & 0.17 \\
12 & 0.75 & 0.27 \\
24 & 0.73 & 0.36 \\
48 & 0.51 & 0.14 \\
72 & 0.34 & -0.18 \\
120 & -0.06 & -0.59 \\
180 & -0.29 & -0.52 \\
240 & -0.22 & -0.48 \\
\hline
\end{tabular}

SSTD computed for large $\tau$ should indicate the opposite tendency. Thus, for $\tau \geq 120 \mathrm{~h}$, Table 5 shows the already negative correlation of air temperature SSTD with NAO indexes. Note here that the negative correlation is weak and slightly overpredicts a $90 \%$ level of significance only for $\tau=180 \mathrm{~h}$. Figure 12 shows January spectra of air temperature at OWS J, averaged over the mid 1960s, known as a period of GA, and the early 1970s, associated with GB (Carleton 1987; Kushnir 1994). The GB spectrum has significantly more power than the GA spectrum in the high-frequency range and less power at periods greater than $3-5$ days. If we consider scalar wind speed SSTD (Table 5), there will be significant negative correlation with the NAO indexes for large $\tau$, although the positive coefficients for $\tau \leq 72 \mathrm{~h}$ are small. Thus, air temperature SSTDs effectively indicate the NAO, if computed for synoptic and subsynoptic scales. Intramonthly variations of the wind speed are considered to be an effective indicator of NAO when they account for the timescales greater than several days.

\section{Discussion}

The results can be discussed from a number of viewpoints. The intramonthly statistics, calculated from sampled data, describe the whole range of short-term variations from several hours to several days. Filtering of the short-term variability with increasing $\tau$ makes it possible to detect changes in the synoptic and subsynoptic activity and in the intensity of regime to regime fluctuations in the midlatitudes. For example, previous averaging with $\tau=3$ days filters out variability associated with relatively fast wave-type cyclones, but retains the variability linked to the slow stationary cyclones and with the changes in the background flow.

The general tendency of mainly decreasing SSTD over time for most parameters at midlatitude OWS (Tables 2 and 3) can be considered as an indicator of reducing cyclone activity during the OWS observation period. This is in agreement with a number of cyclonic and anticyclonic climatology studies over the North Atlantic (Reitan 1974; Colucci 1976; Zishka and Smith 1980; Whittaker and Horn 1981; Lau 1988; Bell and Bosart 1989; Roebber 1989; Schinke 1993; and others). 

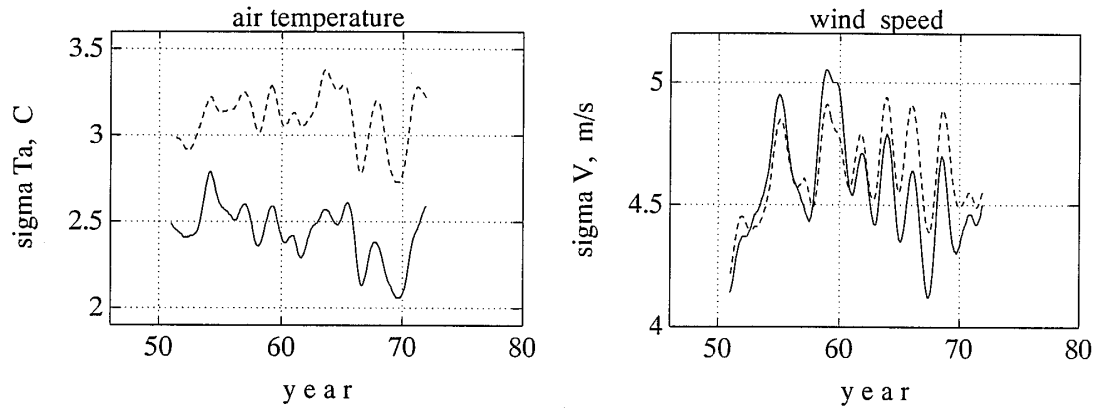

FIG. 13. Long-term variability of the SSTDs of air temperature and scalar wind speed at the location of OWS D (solid lines) and for $8^{\circ} \times 4^{\circ}$ box around OWS D (dashed lines).

All of these works demonstrate a significant decrease in the frequency of cyclones, at least in the west Atlantic between the late 1940s and the early 1970s. This is also consistent with the Kushnir's (1994) analysis, which has depicted the 1960s and early 1970s as a period of the transition from mainly anticyclonic to primarily cyclonic circulation. It is difficult to tell anything about rapidly intensifying cyclones (Sanders and Gyakum 1980; Sanders 1986; Rogers and Bosart 1986; Yau and Jean 1988) and hurricanes due to their relatively infrequent occurrence. Nevertheless, Landsea (1993) published data on the climatology of Atlantic hurricanes. $\mathrm{He}$ has found a significant negative trend in the number of intense hurricanes from 1944 to 1989 . Consideration of the period from 1949 to 1973 gives even more remarkable negative changes. Cyclone statistics are very useful for detecting changes, but they should always be linked with statistical characteristics of synoptic and subsynoptic variability of meteorological variables and fluxes. Our results give numerical estimates of longterm variations of synoptic and subsynoptic activity in terms of meteorological parameters and on different synoptic scales.

The relationships obtained between the interannual changes in intramonthly statistics and SST anomalies indicate quite clearly that the forcing frequency is of the same significance as the forcing magnitude for the anomalous cooling or warming of the ocean. On the other hand, only certain ranges of synoptic variability provide effective forcing, and these scales could be different for different parameters and different seasons. Thus, our results can help to reform the strategy of experimental studies with gridded synoptic-scale data and model experiments focused on finding the mechanisms of observed relationships. In this context one possible line of future investigation would be a study of intramonthly statistics from either climatological datasets (COADS and others) or from the reanalyses of meteorological centers [such as the National Centers for Environmental Prediction (NCEP) or the European Centre for Medium-Range Weather Forecasts (ECMWF)].

COADS Monthly Summary Trimmed Groups (Slutz et al. 1985) contain intramonthly intrabox statistics, used by Zorita et al. (1992) in his study, and individual CMRs make it possible to compute such statistics for requested spatial resolution. Intrabox statistics contain higher numbers of uncertainties than OWS data. Moreover, random observational errors for intrabox statistics are much more inhomogeneous over the North Atlantic. To make a comparison we calculated intramonthly statistics from the original COADS CMR within the $8^{\circ} \times$ $4^{\circ}$ box around OWS D. Figure 13 shows the variability of sampling SSTD, computed from the COADS data and OWS D. Taking into account that from 20\% to 50\% of the total number of the COADS CMRs are data from OWS D, the obtained differences should be considered as evidence of the significant influence of voluntary observing data on the year to year changes in intramonthly statistics. The increase of the mean level of SSTD by $5 \%$ to $20 \%$ (Fig. 13) is as expected due to spatial variability. But the spatial correlation of most of the parameters within a radius of $200-300 \mathrm{~km}$ in this region is relatively high (Gulev and Kolinko 1990), and one does not expect significant differences in the longterm variations of the SSTD, computed from OWS and COADS data. SSTDs of both air temperature and wind speed indicate significant downward trends at OWS D, ranging by $-0.14^{\circ}(10 \mathrm{yr})^{-1}$ and $-0.83 \mathrm{~m} \mathrm{~s}^{-1}(10 \mathrm{yr})^{-1}$, respectively, although there is no evidence of these trends in the statistics computed from $8^{\circ} \times 4^{\circ}$ box data. If we consider the period 1950-65, SSTDs even have a tendency to increase with time, although the trends are not statistically significant. There are also discrepancies in the variability of the SSTDs of other parameters, although they are not as remarkable as for $T_{a}$ and $V$. So in order to use voluntary observing ship data for the consideration of annual and long-term variations of intramonthly statistics, it is necessary to carefully study possible reasons for disagreement between the statistics of these data and the statistics of OWS to find out if the results are physical.

Different meteorological centers now provide analyses with synoptic-scale temporal resolution. Particularly, Hurrell (1995a) and Ayrault et al. (1995) have used a bandpassed ECMWF analysis to describe midlatitude storm tracks. We have compared our SSTD es- 

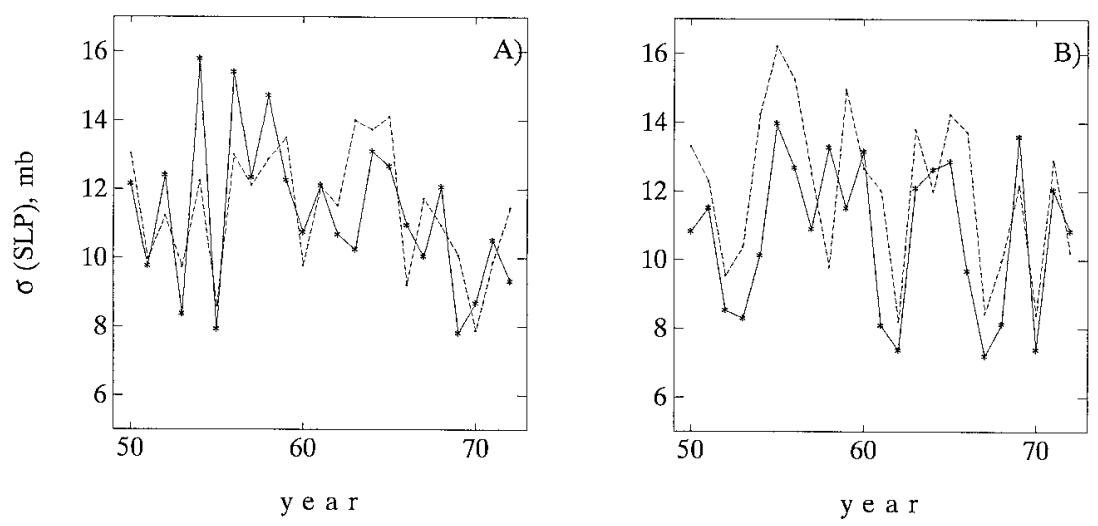

FIG. 14. Long-term variability of January SLP SSTD computed for $\tau=24 \mathrm{~h}$ at the locations of (a) OWS B and (b) OWS D (solid lines), and long-term variability of SSTD of SLP, computed from daily NCEP analyses in the locations of OWSs B and D (dashed lines).

timates for $\tau=24 \mathrm{~h}$ with the intramonthly statistics computed from NCEP daily analysis fields for Januaries for the period 1950-72. Daily SLP values were extracted from NCEP $2.5^{\circ} \times 2.5^{\circ}$ fields in the vicinity of the OWSs. Figure 14 shows the comparisons for OWSs B and D. In contrast to COADS, intramonthly statistics obtained from NCEP analysis show interdecadal variability that is very similar to that obtained from OWS. At the same time, there are visible differences in the magnitude of short-term year to year variations. Remarkable disagreement appears in 1958-59 and 196364 for both OWSs. Future efforts could be connected with the use of the new releases of COADS with corrected biases and with reanalyses, which have nearly the same temporal resolution as OWSs over the entire globe.

Acknowledgments. This study has been done during my work at IFM (Kiel) in 1993 and 1994. I greatly appreciate the attention and support of Prof. Lutz Hasse. I would like to acknowledge Hans-Joerg Isemer of GKSS (Geesthach), who generously supported me by providing data as well as through very productive and useful technical and scientific discussions. I thank Owen Hertzman, Yuri Reva, Stuart Smith, Jean Thiebaux, and Daniel Wright for their helpful comments. Criticism of anonymous reviewers helped very much to improve the paper. This study is supported by Deutsche Forschungsgemeinschaft Sonderforschungsbereich SFB 133 and the Russian Foundation for Basic Research Grant 96-65060.

\section{APPENDIX}

\section{Uncertainties and Errors in Intramonthly Statistics}

The reliability of our results should be considered in light of the errors and uncertainties of intramonthly statistics computed from empirical meteorological data. Estimates of SSTD result from the joint effect of natural variability and random observational errors, which can significantly contribute into both mean SSTD estimates and SSTD spatial and temporal variability. Estimates of random observational errors of marine meteorological observations are presented in the very comprehensive study of Kent et al. (1993) and give from 10\% to $60 \%$ of observed SSTDs for different individual variables. For the high-quality professional observations at OWSs, these estimates should be reduced at least two to three times. Isemer (1994) and Isemer and Lindau (1997, submitted to J. Atmos. Oceanic Technol.) found observational errors of scalar wind speed at OWSs from 0.5 to $1.5 \mathrm{~m} \mathrm{~s}^{-1}$, which are less than half as large as the observational volunteer observing ships errors given by Kent et al. (1993). For the fluxes, which result from the nonlinear combination of individual parameters, random observational errors were studied by Weare (1989), Cayan (1992a), Gulev (1995), and Gleckler and Weare (1995). Again, random errors, taken for more than 100 samples (OWSs usually give more than 200 per month), are several times smaller than observed SSTDs of heat and momentum fluxes. Note here that the consideration of interannual variations of intramonthly statistics reduces the role of observational and sampling errors, which are collected with universal observational techniques and are homogeneous in space and in time.

In section 3 we mentioned two different approaches to estimating air-sea fluxes and their SSTDs. The socalled sampling method implies using the formula (2) for individual variables to obtain the averaged fluxes. Alternatively, we can estimate the averaged fluxes from averaged meteorological parameters for specified $\tau$ (the so-called classical method). Figure A1 shows interannual variability in the SSTDs of sensible and latent heat fluxes at OWSs D and J for two values of $\tau$. The sampling estimates of SSTD are 1.2 to 1.6 times larger than those calculated using the classical method, which is generally consistent with the results of previous investigators (see section 3 for specific references on this 

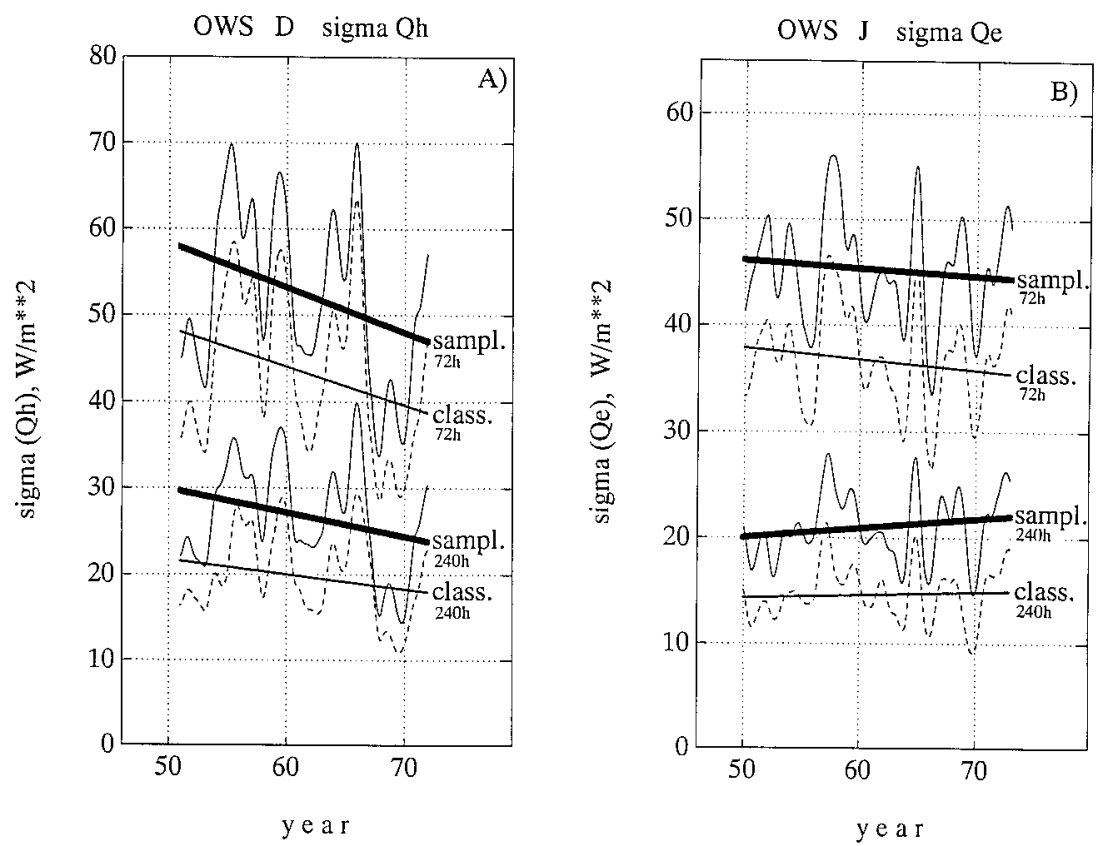

FIG. A1. Comparison of long-term variability of the SSTD of fluxes, calculated from sampling and classical methods for (a) sensible heat flux at OWS D and (b) latent heat flux at OWS J.

topic). However, there is no statistically significant difference either in the linear trends or in the year to year variability estimated by these methods. Other OWSs also indicate very close similarity of the interannual behavior of the SSTD of fluxes computed from classical and sampling methods. The only exception to this statement occurs at OWS M, where the SSTDs of both mo-

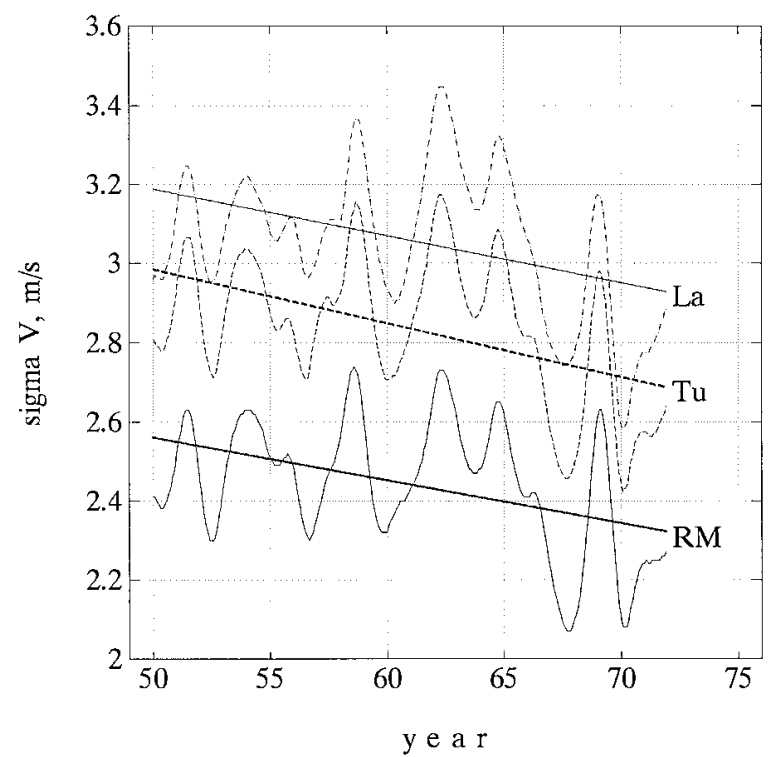

FIG. A2. Comparison of long-term variability of scalar wind speed SSTD at OWS B, computed using running mean (RM, solid line), Tukey filtration (Tu, dashed line), and Lanczos filtration (La, dashdot line) for $\tau=72 \mathrm{~h}$. mentum and latent heat fluxes indicate significantly different trends for $\tau>120 \mathrm{~h}$, and even the change of sign for $\tau=72 \mathrm{~h}$.

A couple of uncertainties can result from statistical procedures, which provide the calculation of intramonthly statistics, taking subsamples at different temporal intervals. The filtering operation creates closer relationships between sequential values (Thiebaux and Pedder 1987). Although the running mean has poor spectral characteristics, it provides the shortest possible window for the selected $\tau$ and, therefore, makes it possible to study a wider range of $\tau$ on the basis of 3-h data. Moreover, the running mean closely simulates the procedure of the data averaging used to produce, say, daily or 3-daily data from the gridded data of a higher separation. To estimate the sensitivity of our results to the use of different filters, we recomputed SSTD for different $\tau$, also using a Tukey filter (Blackman and Tukey 1958) and a Lanczos filter (Lanczos 1956; Duchon 1979), which have quite different response functions from the moving average. Tukey's response function is less steep than those for the running mean, but it has no oscillations in the high-frequency range. Lanczos's filter provides a very effective cutoff of the selected frequency, but creates the Gibbs oscillations, which should be reduced by the smoothing in the frequency range. Figure A2 shows long-term changes of scalar wind speed SSTD, computed using different filters for $\tau=72 \mathrm{~h}$ at OWS B. Both Tukey and Lanczos filtering give slightly higher levels of SSTD in comparison with the running mean. But the features of interannual variability of SSTD and long-term trends are 

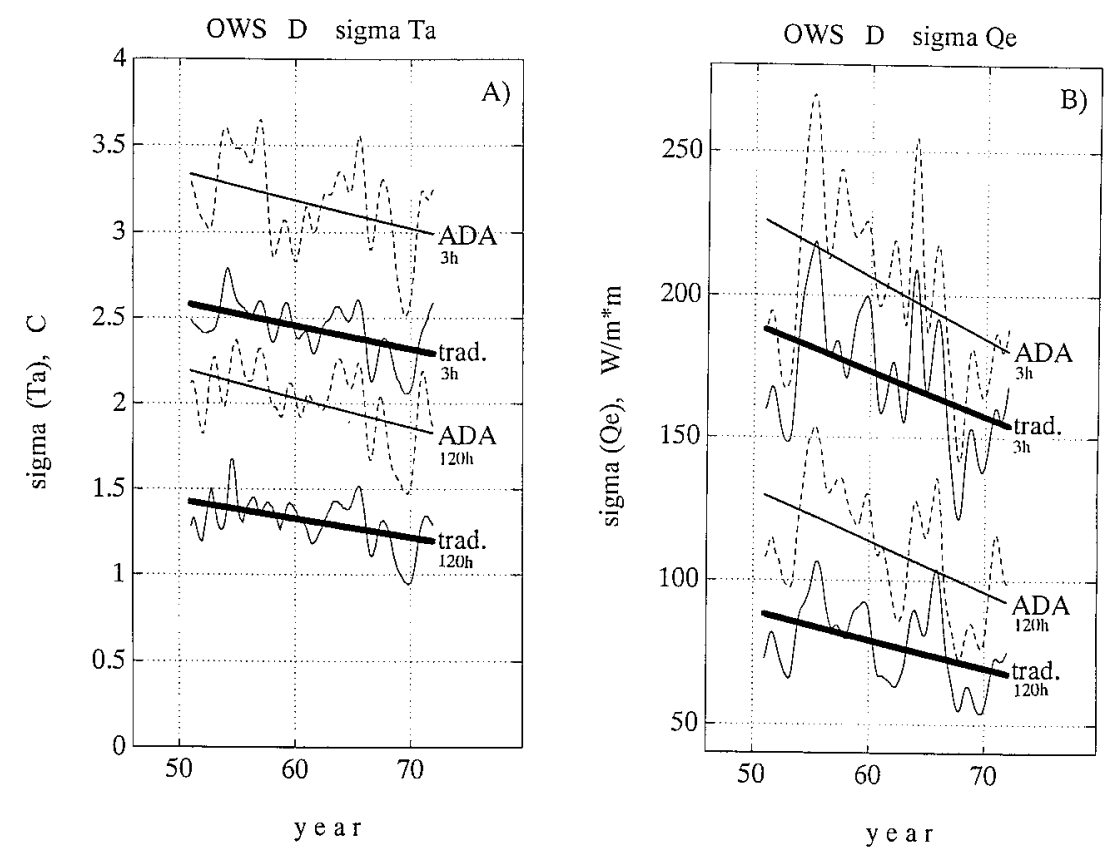

FIG. A3. Comparison of long-term variability of (a) SSTD of air temperature and (b) SSTD of sensible heat fluxes, computed traditionally and using "adjacent days averages" (ADA) in the location of OWS D.

not significantly changed. Plots in Fig. A2 show qualitative coincidence of both trends and short-term interannual variations of SSTD, calculated using different filtering operations.

Thiebaux (1974) notes that traditional variance estimates are biased and suggests that more credible results could be obtained by using moving averages over the adjacent days. To investigate the effect of this bias on our calculations, we computed SSTD using adjacentday averages (ADAs). The comparison of traditional SSTD estimates and ADA estimates for air temperature and for latent heat flux at OWS D is shown in Fig. A3. As in the comparison of sampling and classical approaches, there are significant differences between the mean values of SSTD obtained using the ADA and the traditional approaches. Considering long-term changes, ADA estimates indicate that the slope of the linear trend may be underestimated by between 5\% and $15 \%$ using the traditional method. Estimates of the statistical significance of the obtained changes indicate that statistically significant shifts appear only at OWS M for small $\tau$. At the same time, for the majority of OWS sites, both estimates (even if quantitative differences between them appear) demonstrate, in general, the similar behavior of the trend's slope and sign with $\tau$. So our major conclusions do not depend on the particular variance estimator used in this analysis.

\section{REFERENCES}

Agee, E. M., 1991: Trends in cyclone and anticyclone frequency and comparison with periods of warming and cooling over the Northern Hemisphere. J. Climate, 4, 263-267.
Alexander, M. A., and C. Deser, 1995: A mechanism for the recurrent wintertime midlatitude SST anomalies. J. Phys. Oceanogr., 25, 122-137.

Ariel, N. Z., R. S. Bortkovskiy, S. P. Malevsky, and A. V. Murashova, 1981: Sensible, latent and momentum fluxes calculations over the sea. Meth. comments, 55 pp. [Available from Main Geophysical Observatory, Karbysheva 7, St. Petersburg, Russia.]

Ayrault, F., F. Lalaurette, A. Joly, and C. Loo, 1995: North Atlantic ultra high frequency variability. Tellus, 47A, 671-696.

Barnston, A. G., and R. E. Livezey, 1987: Classification, seasonality, and persistence of low-frequency atmospheric circulation patterns. Mon. Wea. Rev., 115, 1083-1126.

Bell, G. D., and L. F. Bosart, 1989: A 15-year climatology of Northern Hemisphere $500 \mathrm{mb}$ closed cyclone and anticyclone centers. Mon. Wea. Rev., 117, 2142-2162.

Bendat, J. S., and A. G. Piersol, 1966: Measurement and Analysis of Random Data. J. Wiley \& Sons, 390 pp.

Blaauboer, D., G. J. Komen, and J. Reiff, 1982: The behavior of sea surface temperature as a response to stochastic latent and sensible heat forcing. Tellus, 34, 17-28.

Blackman, R. B., and J. W. Tukey, 1958: The measurement of power spectra from the point of view of communications engineering. Bell Syst. Tech. J., 37, 183-282.

Blackmon, M. L., Y. H. Lee, J. M. Wallace, and H. H. Hsu, 1984: Horizontal structure of $500 \mathrm{mb}$ height fluctuations with long, intermediate and short time scales. J. Atmos. Sci., 41, 961-979.

Blanc, T. V., 1985: Variation on bulk-derived surface flux, stability, and roughness due to the use of different transfer coefficient schemes. J. Phys. Oceanogr., 15, 650-669.

Bottomley, M., C. K. Folland, J. Hsiung, R. E. Newell, and D. E. Parker, 1990: Global Ocean Surface Temperature Atlas. U.K. Meteorological Office, 20 pp. and 313 fig.

Branstator, G., 1992: The maintenance of low-frequency atmospheric anomalies. J. Atmos. Sci., 49, 1924-1945.

_ 1995: Organization of storm track anomalies by recurring lowfrequency circulation anomalies. J. Atmos. Sci., 52, 207-226.

Camp, N. T., and R. L. Elsberry, 1978: Oceanic thermal response to strong atmospheric forcing II. The role of one-dimensional processes. J. Phys. Oceanogr., 8, 215-224. 
Cardone, J. S., J. G. Greenwood, and M. A. Cane, 1990: On trends in historical marine wind data. J. Climate, 3, 113-127.

Carleton, A. M., 1988: Meridional transport of eddy sensible heat in winters, marked by extremes of the North Atlantic oscillation, 1948/49-1979/80. J. Climate, 1, 212-223.

Cayan, D., 1992a: Variability of latent and sensible heat fluxes estimated using bulk formulae. Atmos.-Ocean, 30, 1-42.

- 1992b: Latent and sensible heat flux anomalies over the northern oceans: The connection to monthly atmospheric circulation. J. Climate, 5, 354-369.

_ 1992c: Latent and sensible heat flux anomalies over the northern oceans: Driving the sea surface temperature. J. Phys. Oceanogr., 22, 859-881.

Charney, J. G., and J. G. de Vore, 1979: Multiple flow equilibria in the atmosphere and blocking. J. Atmos. Sci., 36, 1205-1216.

Colucci, S. J., 1976: Winter cyclone frequencies over the eastern United States and adjacent western Atlantic, 1964-1973. Bull. Amer. Meteor. Soc., 57, 548-553.

Daly, A. W., 1978: The response of North Atlantic sea surface temperature to atmospheric forcing processes. Quart. J. Roy. Meteor. Soc., 104, 363-382.

Demchenko, P. F., 1987: Simple stochastic model of sea surface temperature anomalies with concomitant changes of air temperature. Izv. Acad. Sci. USSR, Atmos. Oceanic Phys., 23, 532-538.

Deser, C., and M. L. Blackmon, 1993: Surface climate variations over the North Atlantic Ocean during winter: 1900-1989. J. Climate, 6, $1743-1753$.

Diaz, H. F., C. S. Ramage, S. D. Woodruff, and T. S. Parker, 1987: Climatic Summaries of Ocean Weather Stations. NOAA, ERL, CIRES, $48 \mathrm{pp}$.

Draper, N. R., and H. Smith, 1981: Applied Regression Analysis. J. Wiley \& Sons, $710 \mathrm{pp}$.

Duchon, C. E., 1979: Lanczos filtering in one and two dimensions. J. Appl. Meteor., 18, 1016-1022.

Elsberry, R. L., and N. T. Camp, 1978: Oceanic thermal response to strong atmospheric forcing I. Characteristics of forcing events. J. Phys. Oceanogr., 8, 206-214.

—, and R. W. Garwood, 1978: Sea surface temperature anomaly generation in relation to atmospheric storms. Bull. Amer. Meteor. Soc., 59, 786-789.

Esbensen, S. K., and R. W. Reynolds, 1981: Estimating monthly averaged air-sea transfers of heat and momentum using the bulk aerodynamic method. J. Phys. Oceanogr., 11, 457-465.

Fissel, D. V., S. Pond, and M. Miyake, 1977: Computation of surface fluxes from climatological and synoptic data. Mon. Wea. Rev., 105, 26-36.

Frankignoul, C., 1979: Large-scale sea-air interaction and climate predictability. Marine Forecasting, J. C. J. Nihoul, Ed., Elsevier, $35-55$.

_ 1985: Sea surface temperature anomalies, planetary waves, and air-sea feedback in the middle latitudes. Rev. Geophys., 23, 357390.

—_ and K. Hasselmann, 1977: Stochastic climate models: Part 2. Application to sea surface temperature anomalies and thermocline variability. Tellus, 29, 289-305.

— latitude sea surface temperature anomalies. J. Phys. Oceanogr., 13, 1131-1145.

Gleckler, P. J., and B. C. Weare, 1995: Uncertainties in global ocean surface heat flux climatologies derived from ship observations. PCMDI Rep. 26, 39 pp. [Available from PCMDI, LLNL, Livermore, CA 94551.]

Gulev, S. K., 1994: Influence of space-time averaging on the oceanatmosphere exchange estimates in the North Atlantic midlatitudes. J. Phys. Oceanogr., 24, 1236-1255.

_- 1995: Long-term variability of sea-air heat transfer in the North Atlantic Ocean. Int. J. Climatol., 15, 825-852.

- and A. V. Kolinko, 1990: Synoptic variability of the oceanatmosphere heat and water exchange in midlatitudinal ocean frontal zones. Meteor. Hydrol., 9, 85-93. and J. Tonkacheev, 1994: On the parameterization of sea-air interaction over SST fronts in the North Atlantic. Air-Sea Interface, M. A. Donelan, W. H. Hui, and W. J. Plant, Eds., University of Toronto Press, 20-29.

Hanawa, K., and Y. Toba, 1987: Critical examination of estimation methods of long-term mean air-sea heat and momentum transfers. Ocean-Air Interactions, 1, 79-93.

Hannoschoch, G., and C. Frankignoul, 1985: Multivariate statistical analysis of a sea surface temperature anomaly experiment with the GISS general circulation model I. J. Atmos. Sci., 42, 14301450 .

Hasselmann, K., 1976: Stochastic climate models: I. Theory. Tellus, 28, 473-485.

Hayashi, Y., 1982: Confidence intervals of a climatic signal. J. Atmos. Sci., 39, 1895-1905.

Herterich, K., and K. Hasselmann, 1987: Extraction of mixed layer advection velocities, diffusion coefficients, feedback factors, and atmospheric forcing parameters from the statistical analysis of North Pacific SST anomaly fields. J. Phys. Oceanogr., 17, 21452156.

Hurrell, J. M., 1995a: Transient eddy forcing of the rotational flow during northern winter. J. Atmos. Sci., 52, 2286-2301.

_ 1995 b: Decadal trends in the North Atlantic oscillation: Regional temperatures and precipitation. Science, 269, 676-679.

Husby, D. M., 1980: A comparison of surface heat flux estimates from Ocean Weather Station V and merchant vessels in its vicinity in the western North Pacific region, 1956-1970. J. Phys. Oceanogr., 10, 971-975.

Isemer, H.-J., 1994: On the homogeneity of surface wind speed records from Ocean Weather Stations. Tech. Rep., Institute für Meereskunde, Kiel, Germany, 81 pp. [Available from Institut für Meereskude, Dusternbroker Weg 20, Kiel, Germany.]

_ 1995: Trends in marine surface wind speed: Ocean Weather Stations versus voluntary observing ships. Proc. Int. COADS Winds Workshop, Kiel, Germany, NOAA-ERL, 68-84.

Iwasaka, N., and J. M. Wallace, 1995: Large scale air sea interaction in the Northern Hemisphere from a view point of variations of surface heat flux by SVD analysis. J. Meteor. Soc. Japan, 73, 781-793.

Jones, P. D., 1988: Hemispheric surface air temperature variations: Recent trends and an update to 1987. J. Climate, 1, 654-660.

Kent, E. C., and P. K. Taylor, 1995: A comparison of sensible and latent heat flux estimates for the North Atlantic Ocean. J. Phys. Oceanogr., 25, 1530-1549.

,-- , B. S. Truscott, and J. S. Hopkins, 1993: The accuracy of voluntary observing ships' meteorological observations-Results of the VSOP-NA. J. Atmos. Oceanic Technol., 10, 591608.

Kushnir, Y., 1994: Interdecadal variations in North Atlantic sea surface temperature and associated atmospheric conditions. J. Climate, 7, 142-157.

Lamb, P. J., and R. A. Peppler, 1987: North Atlantic oscillation: Concept and an application. Bull. Amer. Meteor. Soc., 68, 1218 1225.

Lanczos, C., 1956: Applied Analysis. Prentice-Hall, 539 pp.

Landsea, C. W., 1993: A climatology of intense (or major) Atlantic hurricanes. Mon. Wea. Rev., 121, 1703-1713.

Lappo, S. S., A. G. Muzychenko, and S. H. Rosenfeld, 1987: On stochastic structure of the North Pacific SST anomalies. Meteor. Hydrol., 3, 58-65.

Lau, N.-C., 1988: Variability of the observed midlatitude storm tracks in relation to low-frequency changes in the circulation pattern. J. Atmos. Sci., 45, 2718-2743.

Ledvina, D. L., G. S. Young, R. A. Miller, and C. W. Fairall, 1993: The effect of averaging on bulk estimates of heat and momentum fluxes for the tropical western Pacific Ocean. J. Geophys. Res., 98, $20211-20217$.

Legler, D., 1991: Errors in five-day mean surface wind and temperature conditions due to inadequate sampling. J. Atmos. Oceanic Technol., 8, 705-712. 
Leith, C. E., 1973: The standard error of time-average estimates of climatic means. J. Appl. Meteor., 12, 1066-1069.

Levin, B. R., 1974: Theoretical principals of the statistical radiotechnics. Soviet Radio, 548 pp.

Liu, W. T., K. B. Katsaros, and J. A. Businger, 1979: Bulk parameterization of air-sea exchanges of heat and water vapor including the molecular constraints at the interface. J. Atmos. Sci., 36, $1722-1735$.

Marsden, R. F., and S. Pond, 1983: Synoptic estimates of air-sea fluxes. J. Mar. Res., 41, 349-373.

Miller, D. K., and K. B. Katsaros, 1992: Satellite-derived surface latent heat fluxes in a rapidly intensifying marine cyclone. Mon. Wea. Rev., 120, 1093-1107.

Mobley, C. D., and R. W. Preisendorfer, 1985: Statistical analysis of historical climate data sets. J. Climate Appl. Meteor., 24, 555567.

Namias, J., and R. M. Born, 1970: Temporal coherence in North Pacific sea-surface temperature patterns. J. Geophys. Res., 75, $5952-5955$.

Oort, A. H., Y. H. Pan, R. W. Reynolds, and C. F. Ropelewski, 1987: Historical trends in the surface temperature over the oceans, based on the COADS. Climate Dyn., 2, 29-38.

Peterson, E. W., and L. Hasse, 1987: Did the Beaufort scale or the wind climate change? J. Phys. Oceanogr., 17, 1071-1074.

Pitterburg, L. I., 1989: Dynamical-Stochastic Models of Sea Surface Temperature Anomalies. Gidrometeorzdat, $212 \mathrm{pp}$

Ramage, C. S., 1984: Can shipboard measurements reveal secular changes in tropical air-sea heat flux? J. Climate Appl. Meteor., 23, 187-193.

Reitan, C. H., 1974: Frequencies of cyclones and cyclogenesis for North America, 1951-1970. Mon. Wea. Rev., 102, 861-868.

Robertson, A. W., and W. Metz, 1990: Transient eddy feedbacks derived from linear theory and observations. J. Atmos. Sci., 47, 2743-2764.

Roebber, P. J., 1989: On the statistical analysis of cyclone deepening rates. Mon. Wea. Rev., 117, 2293-2298.

Rogers, E., and L. F. Bosart, 1986: An investigation of explosively deepening oceanic cyclones. Mon. Wea. Rev., 114, 702-718.

Rogers, J. C., 1984: The association between the North Atlantic oscillation and the Southern Oscillation in the Northern Hemisphere. Mon. Wea. Rev., 112, 1999-2015.

Sanders, F., 1986: Explosive cyclogenesis in the west-central North Atlantic Ocean. Mon. Wea. Rev., 114, 1781-1794.

—, and J. R. Gyakum, 1980: Synoptic-dynamic climatology of the "bomb." Mon. Wea. Rev., 108, 1589-1606.

Schinke, H., 1993: On the occurrence of deep cyclones over Europe and the North Atlantic in the period 1930-1991. Beitr. Phys. Atmos., 66, 223-237.

Schmidt, H., and H. von Storch, 1993: German bight storms analysed. Nature, 370, 791.

Slutz, R. J., S. J. Lubker, J. D. Hiscox, S. D. Woodroof, R. L. Jenne, D. H. Joseph, P. M. Steurer, and J. D. Elms, 1985: Comprehensive
Ocean-Atmosphere Data Set: Release 1. NOAA Environmental Research Laboratory, 268 pp.

Smith, S. D., and F. W. Dobson, 1984: The heat budget at Ocean Weather Station Bravo. Atmos.-Ocean, 22, 1-22.

Thiebaux, H. J., 1974: Estimation of covariances of meteorological parameters using local-time averages. J. Appl. Meteor., 13, 592600.

—, and M. A. Pedder, 1987: Spatial Objective Analysis with Applications in Atmospheric Science. Academic Press, 229 pp.

Ueno, K., 1993: Interannual variability of surface cyclone tracks, atmospheric circulation patterns, and precipitation patterns in winter. J. Meteor. Soc. Japan, 71, 655-671.

van Loon, H., and J. C. Rogers, 1978: The seesaw in winter temperatures between Greenland and Northern Europe. I: General description. Mon. Wea. Rev., 106, 296-310.

von Storch, H., and Coauthors, 1993: Changing statistics of storms in the North Atlantic. Max-Planck-Institute Meteor. Rep. 116, 19 pp. [Available from MPI, Bundestrasse, 55, Hamburg, Germany.]

Wallace, J. M., C. Smith, and Q. Jiang, 1990: Spatial patterns of atmosphere-ocean interaction in the northern winter. J. Climate, 3, 990-998.

Ward, M. N., 1992: Provisionally corrected surface wind data, worldwide ocean-atmosphere surface fields, and Sahelian rainfall variability. J. Climate, 5, 454-475.

Weare, B. C., 1977: Empirical orthogonal analysis of Atlantic Ocean surface temperature. Quart. J. Roy. Meteor. Soc., 103, 467-478.

_ 1989: Uncertainties in estimates of surface heat fluxes derived from marine reports over the tropical and subtropical oceans. Tellus, 41A, 357-370.

— 1993: Multi-year statistics of selected variables from the ISCCP C2 data set. Quart. J. Roy. Meteor. Soc., 119, 795-808.

— calculated monthly mean oceanic surface heat fluxes. Tellus, 33, 211-224.

Whittaker, L. M., and L. H. Horn, 1981: Geographical and seasonal distribution of North American cyclogenesis, 1958-1977. Mon. Wea. Rev., 109, 2312-2322.

Willebrand, J., 1978: Temporal and spatial scales of the wind field over the North Pacific and North Atlantic. J. Phys. Oceanogr., 8, 1080-1094.

Woodward, W. A., and H. L. Gray, 1993: Global warming and the problem of testing for trend in time series data. J. Climate, $\mathbf{6}$, 953-962.

Yau, M. K., and M. Jean, 1989: Synoptic aspects and physical processes in the rapidly intensifying cyclone of 6-8 March 1986. Atmos.-Ocean, 27, 59-86.

Zishka, K. M., and P. J. Smith, 1980: The climatology of cyclones and anticyclones over North America and surrounding ocean environs for January and July, 1950-1977. Mon. Wea. Rev., 108, 387-401.

Zorita, E., V. Kharin, and H. von Storch, 1992: The atmospheric circulation and sea surface temperature in the North Atlantic area in winter: Their interaction and relevance for Iberian precipitation. J. Climate, 5, 1097-1108. 